\title{
WORLD INCOME COMPONENTS: MEASURING AND EXPLOITING INTERNATIONAL RISK SHARING OPPORTUNITIES
}

Robert J. Shiller

Stefano Athanasoulis

Working Paper No. 5095

\section{NATIONAL BUREAU OF ECONOMIC RESEARCH 1050 Massachusetts Avenue \\ Cambridge, MA 02138 \\ April 1995}

The authors are indebted to David Backus, Maurice Obstfeld, Kenneth Rogoff and Xavier Sala-iMartin for helpful discussions. This research was supported by the U.S. National Science Foundation. This paper is part of NBER's research program in Asset Pricing. Any opinions expressed are those of the authors and not those of the National Bureau of Economic Research.

(C) 1995 by Robert J. Shiller and Stefano Athanasoulis. All rights reserved. Short sections of text, not to exceed two paragraphs, may be quoted without explicit permission provided that full credit, including (C) notice, is given to the source. 


\title{
WORLD INCOME COMPONENTS: MEASURING \\ AND EXPLOITING INTERNATIONAL RISK \\ SHARING OPPORTUNITIES
}

\begin{abstract}
We provide methods of decomposing the variance of world national incomes into components in such a way as to indicate the most important risk-sharing opportunities, and, therefore, the most important missing international risk markets to establish. One method uses a total variance reduction criterion, and identifies risk-sharing opportunities in terms of eigenvectors of a variance matrix of residuals produced when country incomes are regressed on world income. Another method uses a mean-variance utility-maximizing criterion and identifies risk-sharing opportunities in terms of eigenvectors of a variance matrix of deviations of country incomes from their respective contract-year shares of world income.

The two methods are applied using Summers-Heston (1991) data on national incomes for large countries 1950-1990, each using two different methods of estimating variances. While these data are not sufficient to provide accurate estimates of the requisite variance matrices of (transformed) national incomes, the results are suggestive of important new markets that could actually be created, and show that there may be large welfare gains to creating some of these markets.
\end{abstract}

Robert J. Shiller

Cowles Foundation

Yale University

30 Hillhouse Avenue

New Haven, CT 06520-8281

and NBER
Stefano Athanasoulis

Department of Economics Iowa State University

Ames, IA 50011 
In this paper, we develop methods for characterizing the risk structure of world incomes and for producing definitions of a small number of securities that will allow us to create new markets for much of this risk. Our methods are related to principal components analysis applied to national incomes (strictly speaking, gross domestic products, GDPs), of the nations of the world. Our methods take account of the relative size and variability of different countries' incomes, as well as the tendency of certain national incomes to move together, to suggest the most important opportunities for risk sharing. Our methods differ from standard principal components analysis applied to national incomes in that ours are variance decompositions of risk-sharing opportunities, not of national incomes themselves. Our data consist of the Penn World Table data on annual real per capita GDPs for the twelve largest (in terms of 1990 GDP) countries 1950-90, measured in 1985 US dollars; see Summers and Heston (1991). ${ }^{1}$

A product of our analysis is a set of world income components, or indexes (that is, linear combinations) of national incomes, designed to be used as the basis of settlement for risk management contracts. We will refer to the contracts, claims on components of world incomes, as income component securities; we would expect these contracts to be traded on securities markets just as other securities are traded today. They might also be called income component futures contracts and be traded at futures exchanges. ${ }^{2}$ Some of our proposed securities can be described as

\footnotetext{
'Our methods have some similarities to one suggested in the theoretical paper of Duffie and Jackson (1989).

${ }^{2}$ The proposed contracts have aspects of both securities and futures. The "index participations" traded at the American Stock Exchange and the Philadelphia Stock Exchange in 1989 are analogous to the securities defined here; their trading launched a debate on whether they are securities or futures, and thus on how they should be regulated; see Shiller (1993a).
} 
insurance policies for certain groups of countries; calling a security an insurance policy is most appropriate when the variation in the index is highly negatively correlated with the income of one country, and the people in that country buy the security to reduce their income risk. Some of the income component securities can also be described as swaps of certain groups of national incomes for other groups; calling a security a swap is most appropriate when the index gives negative weights to roughly half of the national incomes. ${ }^{3}$ Our analysis does not begin with any preconceived notions whether we want to create insurance policies or swaps, or any other instrument: our analysis goes directly for the most advantageous risk-sharing arrangement.

Our study of risk-sharing opportunities among national incomes is potentially very important, since national incomes are measures of total economic welfare of the countries, and since there have been historically large variations in real national incomes. Moreover, there is very little effective risk diversification across nations today (see, for example, Obstfeld, 1993; Tesar and Werner, 1993). We will do a consumersurplus analysis below that will further confirm the importance of our proposed markets.

In Shiller (1993a) (see also Shiller, 1993b) it was proposed that markets be established for long-term, even perpetual, claims on national incomes; it was argued that, despite some potential problems, such markets are indeed feasible. Here, our income component securities will be defined as finite-term, $T$-year, claims on the indexes (linear combinations)

\footnotetext{
${ }^{3}$ We shall see below that even when our optimal securities can be thought of roughly as insurance policies, those that are defined by the second of our two methods below are really also always swaps since a swapping of risks is always involved with an optimally defined contract.
} 
of national incomes defined here. In our empirical work below we will consider securities with $T$ of both ten and forty years. Ideally, there would eventually be securities for an array of horizons and for perpetual securities, so that people with different circumstances in terms of years of life expected or number of heirs could find a security tailored to their interests.

Because there do not now exist any markets for national incomes or for any large income aggregates, when we set up any such markets we must consider how they would work pretty much in isolation. Existing markets are very small in comparison: Our stock and bond markets are claims on only a tiny fraction of national incomes; for example, dividends account for only about $3 \%$ of US national income. Real estate is mostly highly illiquid, and costly to diversify, and in any event real estate income is also a small component of national incomes.

In attempting to define a small number of income component securities markets that will allow maximal risk sharing given the number of markets, we seek to define the best first market to set up, as well as the best second or third markets. We assume that the number of markets introduced must be kept small, especially at the beginning. By analogy, there are not many stock index futures markets in the world, indeed, from a world perspective, not many aggregate liquid risk management markets at all.

Another reason for confining our attention to only one or a few markets is that it is useful for us to be able to prescribe in simple terms the most important risk management actions that should be taken by large groups of people. Simple prescriptions are what most people take from existing models. The mean-variance capital asset pricing model (CAPM) in finance, to which our methods are related, is most often used by 
practitioners not to arrive at complicated definitions of optimal portfolios, but just for the simple prescription that investors should hold the market portfolio of investable assets, and we now have many indexed funds that were designed to allow them to do just this. The problem with this commonly-given prescription is that it is not really the logical consequence of the foundations of the CAPM, since it disregards the correlation of investment returns with innovations in the present value of other income, other income which is much larger in the aggregate than income from existing investable assets. We seek here to devise methods to replace this simple prescription associated with the CAPM with a more sensible simple prescription, though any such prescription cannot be taken until the new markets are created.

We shall assume that the earnings people make in the new income component securities markets are consumed, not invested either in physical capital or in technological research, so that we do not need to calculate the effects of investments on future income suggested by models of Romer (1990), Grossman and Helpman (1991), and Obstfeld (1995). We also disregard the fact that a component of national incomes is nontradable, see Baxter, Jermann and King (1994). Making adjustments in our analysis for such considerations is possible; we leave that to future research.

We pursue two approaches to defining world income components, i.e., income indices, so that long-term claims on the indices can be traded for risk management. The first (Section II below) is a pure variance reduction strategy. With this strategy, in defining the income component securities, we assume that individuals in each country are interested only in reducing the variance of their income, and we constrain the ex ante price of the securities $P$ to equal zero. We seek to define contracts such that excess 
demand is zero at a zero initial price for the securities, for countries that seek only to reduce risk in trading these securities. We then seek to define a small number of securities that allow for the most overall risk reduction through risk sharing subject to the restriction on the number of securities. With this strategy, the method of defining securities has a clear and simple relation to principal components analysis: it turns out that the optimal securities are defined in terms of eigenvectors of a sort of variance matrix of residuals produced when national incomes are regressed on world income.

A problem with our first method is that it does not allow any country to pay, in effect, a price, analogous to an insurance premium or to the schedule of fixed cash transfers that is part of some swaps between risky assets, ${ }^{4}$ to induce another country to assume some of its risk. The second method (Section III below) is a utility-maximization-based method, that assumes that countries have known identical utility functions, and derives an expression for the prices of the income component securities in general equilibrium. Securities are then defined so as to maximize social welfare. It turns out that the optimal securities are defined in terms of eigenvectors of a sort of variance matrix of deviations of national incomes from their respective contract-year shares of world income. Having made a specification of utility functions, we are able with our second method to derive estimates of the consumer surplus generated by the creation of the new contracts.

In Section IV below, we discuss how to apply our two methods of defining the income component securities to the data. Two methods of

${ }^{4}$ See Kapner and Marshall (1990) for a description of the institutional details of such swaps. 
estimating variance matrices of national incomes are also used, a method that uses sample moments directly and a method that uses strong prior restrictions to estimate. In Section $\mathrm{V}$ we present results for both ten countries (unrestricted variance matrix) and twelve countries (restricted variance matrix), and in Section VI we interpret these results as suggesting genuine opportunities for important new markets.

\section{DEFINITION OF CONTRACTS AND RISK STRUCTURE}

In each of the new markets to be created, income component securities are to be traded that represent claims on a stream of world income components, that is, of index values, according to a standard contract specified by the securities or futures exchange. ${ }^{5}$ At the beginning of a contract in the $q$ th market, at contract year 0 , the long in the contract agrees to pay, each contract year from $t=1$ to $T$, an amount $P_{q r}=P_{q}(1+g)^{t}$ to the short in the contract, and to receive from the short $R_{q r}$, the year $t$ "dividend" paid on the income component security, to be determined in year $t$ according to a linear formula defined in the contract in year 0 . The parameter $P_{q}$, which we will call the price of the contract, and the growth rate $g$, which we take equal to the anticipated average growth rate of real per capita gross domestic products, specified to keep the payment in line with expected growth of incomes, are specified in the original contract at year 0 . The dividend $R_{q t}$ is our $q$ th world income component at year $t$, a linear function of national incomes accruing to year 0 populations in that year. National incomes in year $t$ accruing to year 0 populations (which we

\footnotetext{
${ }^{5} \mathrm{~A}$ table of symbols and a table of basic relations appear near the end of this paper.
} 
will refer to here loosely as national incomes) are taken here to be per capita gross domestic products in year $t$ times the corresponding populations of year 0 . We will assume that each contract signer individually can be expected to earn his or her share of the per capita national income in subsequent years from sources other than the contracts we define here. The linear function of national incomes specifying the dividend is defined in the initial contract at year 0 so that the present value over $T$ years of the function is defined to have an expectation, conditional on information at year 0 , of 0 . We are assuming here that public expectations of future real per capita national incomes are objective public knowledge, so that contracts can be written in terms of these expectations, though in practice some rough proxy for the expectations would have to be used by contract designers. Our use of expectations in the contract definition is essentially only a normalization rule for price; if contract designers misrepresent public expectations when they design the contract, then the result will only be a change in the market-clearing contract price; the initial contract price at year 0 will then not have the interpretation we give it. Even if they do specify the expectations correctly at year 0 , as time goes by, there will be new information about expected future national incomes, and so the conditional expectations of the present value of the linear function of national incomes at the future dates will no longer be zero. New contracts, initiated after year 0 that also expire at $T$ will have different prices, and those who entered a contract at year 0 and wish to get out of the contract before year $T$ will have to make a settlement in terms of the new price. However these future sales are not our focus of attention here. We study the contracts from the standpoint of the year they are initiated, year 0 , only.

Let us define the $1 \times C$ random vector $X$ whose $c$ th element, $c=1$, 
$\ldots, C$, is the present value in year 0 (the year the contract is made) of real per capita national income for country $c$ for the years 1 through $T$ minus the expectation at year 0 of this present value, all times population of country $c$ in year $0 .^{6}$ Thus, taking $E_{0}$ as the expectations operator conditional on information available at year 0 , we have that $E_{0} X=0$ and the conditional variance matrix for $T$-year present value of national incomes accruing to current populations is $\mathbf{\Omega}=E_{0}\left(X^{\prime} X\right) . X$ will be redefined as a $T \times C$ matrix and $\mathbf{Q}$ will have a different interpretation in Section III below.

The $q$ th income component security has a present value of dividend payout $R_{q v}, t=1, \ldots, T$, equal to $R_{q}=X A_{q}$, where $A_{q}$ is a $C \times 1$ element vector whose $c$ th element is the fraction of national income of country $c$ that is paid as part of the dividend on one security in market $q$. Assuming that there will be $Q$ different kinds of securities traded, $0<Q<C$, let us create a $Q$-element vector $R$ whose $q$ th element is $R_{q}$ and a $C \times Q$ matrix $A$ whose $q$ th column is $A_{q}$. Then, $R$ equals $X A$, and $R$ will be the present value of our desired vector of world income components, i.e., index values. ( $R$ will be redefined in Section III below as a $T \times Q$ matrix.)

Let us suppose that the portfolio weights $\boldsymbol{A}$ defining the securities are normalized so that $E\left(R^{\prime} R\right)=I$, where $I$ is the $Q \times Q$ identity matrix. This normalization means that the variance of the present value of $T$ years of dividends (dividends measured in thousands of 1985 dollars), summing from $t=1, \ldots, T$, is one, and the covariances of the present value of $T$

\footnotetext{
${ }^{6}$ In practice, we use real gross domestic product to proxy for national income. We use a constant real discount rate, the same for all countries, equal in our empirical work below to $2 \%$.
} 
years of dividends with the present values of $T$-years of dividends of all other markets are zero. This normalization has no effect on the market's ability to form portfolios using the securities. The normalization will have the effect of tending to make the elements of $\boldsymbol{A}$ very small, so that contract size is suitable for trading by individuals.

\section{THE PURE VARIANCE REDUCTION METHOD OF DESIGNING SECURITIES}

With the pure variance reduction method of this section, we seek to design income component securities whose price $P$ defined at the date of the beginning of the contract, $t=0$, is zero. Designing contracts whose price is zero initially is analogous to underwriters' designing bonds to sell at par on issue. Note that since we have demeaned national incomes, trading in the zero-price contracts at the initial date bas no effect on one's expected, as of that date, present value of future income.

A representative individual in country $c$ seeking at year 0 to hedge his or her income risk can minimize the variance of $T$-year present value of income in terms of the $Q$ securities by regressing minus his or her share in the $T$-year present value of national income of country $c$ onto the $Q$ $T$-year present values of dividends. The vector of the sum across all individuals in country $c$ of theoretical regression coefficients is $\beta_{c}$ $=-E\left(R^{\prime} R\right)^{-1} E\left(R^{\prime} X_{\partial}\right.$. Since $E\left(R^{\prime} R\right)=I, \beta_{c}=-E\left(R^{\prime} X_{\partial}=-A^{\prime} \Omega_{c}\right.$ where $\mathbf{\Omega}_{c}$ is the $c$ th column of $\mathbf{\Omega}$. The optimal hedge for country $c$ (individuals in country $c$ considered together) will be to purchase a number $\beta_{q c}$ of the qth security so that the unexpected component of that country's income is offset as well as possible by opposite dividends in the portfolio of secu- 
rities, minimizing the variance of the combined incomes. ${ }^{7}$ Let us combine the $C$ vectors $\beta_{c}, c=1, \ldots, C$ into a $Q \times C$ matrix $\beta$ whose $q$ th column is $\beta_{q}$, and so $\beta=-A^{\prime} \boldsymbol{\beta}$. It may seem unrealistic to assume, as we do, that everyone hedges; however our analysis would have been unaffected had we assumed that only a fraction of the population hedges, so long as this fraction did not vary across countries.

Let us now infer how designers of new markets might construct the $Q$ securities in such a way that they would allow the best possible compromise over the $C$ countries, for the purpose of allowing them to hedge well. Obviously, any given country would prefer that a market be set up specifically for hedging risks to this country's income, but such a market might not serve other countries well. To achieve a compromise, we want to minimize a weighted average of the various countries' hedging error. This means that the designer must select the matrix $A$ (select terms of the contract) to minimize, by some metric, the combined errors made by everyone. The metric for the combined expected squared errors that we will use is $S=\operatorname{tr}\left(w E_{0}\left((X+R \beta)^{\prime}(X+R \beta)\right)\right)$, where $w$ is a diagonal matrix with strictly positive elements along the diagonal. $S$ is the expected squared error for each country $c$ weighted by $w_{c}$ (the $c$ th diagonal element of $w$ ) and summed across countries. In our empirical work with this method, we will make $w=I$ so that all countries have the same weight.

Now, note that $S=\operatorname{tr}\left(w E_{0}\left((X+R \beta)^{\prime}(X+R \beta)\right)\right)=\operatorname{tr}\left(w \Omega-w \Omega A A^{\prime} \Omega\right)$ $=\operatorname{tr}(w \Omega)-\operatorname{tr}\left(A^{\prime} \Omega w \Omega A\right)$. To minimize $S$, we must maximize $\operatorname{tr}\left(A^{\prime} \Omega_{w \Omega A}\right)$ subject to the constraint $A^{\prime} \mathbf{Q} A=I$. Moreover, we have an additional

\footnotetext{
${ }^{7} \beta_{q c}$ is measured in units of number of contracts for each country, so that $\beta_{q c}$ will presumably be a very large number, in contrast to the very small value of $\boldsymbol{A}_{c q}$.
} 
constraint that the total positions are zero; for every short there must be a long; this constraint represents the essential motivation in our analysis that we are looking for risk-sharing opportunities, not just ordinary principal components of income. Thus, we have that $\beta_{\mathfrak{t}}=0$, where $\iota$ is a $C \times 1$ vector of ones.

Let us first solve this maximization problem for the case of only one market, where the matrix $A$ is a column vector. To maximize subject to the two constraints $A^{\prime} \Omega_{A}=1$ and $A^{\prime} \Omega_{L}=0$ we set up the Lagrangian $L$ :

$$
L=A^{\prime} \mathbf{Q} w \mathbf{\Omega} A-\left(A^{\prime} \mathbf{\Omega} A-1\right) \lambda-\left(A^{\prime} \mathbf{Q} \iota\right) \mu
$$

where $\lambda$ and $\mu$ are Lagrange multipliers for the two constraints. Differentiating with respect to $A$, we derive the first order condition:

$$
\partial L / \partial A=20 w \Omega A-2 \Omega A \lambda-Q_{L \mu}=0
$$

Premultiplying the above equation by $A^{\prime}$, and, using the facts that $A^{\prime} \Omega_{l}$ $=0$ and $A^{\prime} \Omega A=1$, we show that $\lambda=A^{\prime} \Omega w \Omega A=\beta w \beta^{\prime} ;$ this is the total weighted variance reduction, the weighted sum of the variance reductions across all countries. Premultiplying by $\iota^{\prime}$, we also show, again using $A^{\prime} \Omega_{\iota}$ $=0$, that $\mu=2 \iota^{\prime} \mathbf{Q}_{w n} \boldsymbol{A} /\left(\iota^{\prime} \mathbf{Q}_{\iota}\right)$. Substituting for $\mu$ in equation (2), we find:

$$
\left(w \Omega-\imath\left(\imath^{\prime} \mathbf{Q}\right)^{-1} \imath^{\prime} \Omega w \Omega\right) A=A \lambda
$$

so that $\boldsymbol{A}$ is proportional to an eigenvector, and $\lambda$ is the corresponding eigenvalue, of the matrix that premultiplies $A$ on the left hand side. It is instructive to write the same equation in terms of $\beta$ :

$$
\begin{aligned}
& \left(\mathbf{\Omega}-\mathbf{\Omega}_{\iota}\left(\iota^{\prime} \mathbf{\Omega}_{\imath}\right)^{-1} \iota^{\prime} \mathbf{Q}\right) w \beta^{\prime}=M^{\prime} \mathbf{Q} M w \beta^{\prime}=\beta^{\prime} \lambda \\
& M=I-\imath\left(\iota^{\prime} \mathbf{\imath} \iota\right)^{-1} \iota^{\prime} \mathbf{Q}
\end{aligned}
$$

It will be recognized that the matrix $M$ defined in the above expression is the idempotent matrix such that $X M$ is the matrix whose $i$ th element is the 
residual when the $i$ th column of $X$ (ith country's demeaned present value of income) is regressed on world present value of income. Thus, $M^{\prime} \Omega M$ (which equals $\mathbf{D M}$ ) is the variance matrix of residuals for each country, when each country's $X$ is regressed on world present value of income $X \boldsymbol{l}$, and hence, if $w=I, \beta^{\prime}$ is (proportional to) an eigenvector of this matrix. Our world income component $R$ is $X A$ (which equals $-X \Omega^{-1} \beta^{\prime}$ ); this is, if $w=I$, proportional to the first principal component of $X M$, that is to $X M \beta^{\prime}$. To see this point, write $X M \beta^{\prime}$ as $X \Omega^{-1} \Omega M \beta^{\prime}$ and use the fact that $\mathbf{Q} \boldsymbol{M} \boldsymbol{\beta}^{\prime}=\beta^{\prime} \lambda$.

Having solved the one-component case, let us now move to the general case. Disregarding, for the moment, the constraint that the $A^{\prime} \Omega A$ should be diagonal, requiring only that its diagonal elements be one, we set up the Lagrangian:

$$
L=\operatorname{tr}\left(A^{\prime} \Omega \omega \Omega A\right)-\sum_{q=1}^{Q}\left(A_{q}^{\prime} \Omega A_{q}-1\right) \lambda_{q}-\iota^{\prime} \Omega A \mu
$$

where $\lambda_{q}, q=1, \ldots, Q$ are Lagrange multipliers for the constraint that diagonal elements of $A^{\prime} \Omega A$ equal one, and where $\mu$ is the $Q \times 1$ vector of Lagrange multipliers for the market clearing constraints. Differentiating with respect to the matrix $A$, we find:

$$
\frac{\partial L}{\partial A}=2 \Omega w \Omega A-2 \Omega A \Lambda-\Omega \iota \mu^{\prime}=0
$$

where $\Lambda$ is a $Q \times Q$ diagonal matrix with the $\lambda_{q}$ along the diagonal. Premultiplying (6) by $A^{\prime}$, we see that $A^{\prime} \Omega A \Lambda=A^{\prime} \Omega w \Omega A$. Premultiplying (6) by $\imath^{\prime}$, one finds that $\mu^{\prime}$ equals $2 \imath^{\prime} \Omega w \Omega A /\left(\imath^{\prime} \Omega_{\imath}\right)$. Substituting in (6) for $\mu^{\prime}$, we then have:

$$
\left(w \Omega-\iota\left(\iota^{\prime} \Omega_{\imath}\right)^{-1} \iota^{\prime} \Omega w \Omega\right) A=A \Lambda
$$


or, in terms of $\beta$ :

$$
\begin{gathered}
\left(\Omega-\Omega_{\iota}\left(\iota^{\prime} \Omega_{\imath}\right)^{-1} \iota^{\prime} \Omega\right) w \beta^{\prime}=M^{\prime} \Omega M w \beta^{\prime}=\beta^{\prime} \Lambda \\
M=I-\iota\left(\iota^{\prime} \Omega \iota\right)^{-1} \iota^{\prime} \Omega
\end{gathered}
$$

Premultiplying (8) by $w^{.5}$, we see from the above expression that $w^{5} \beta$ has columns proportional to eigenvectors of the real nonnegative definite symmetric matrix $w^{.5} M^{\prime} \Omega M w^{.5}$, and hence $\beta w \beta^{\prime}$ is diagonal. Using $\beta$ $=-A^{\prime} \Omega$, we see that $A^{\prime} \Omega w \Omega A$ is also diagonal, and hence, using $A^{\prime} \Omega A \Lambda$ $=A^{\prime} \Omega w \Omega A$, we see that $A^{\prime} \Omega A$ is diagonal too, so the constraints that were not represented in the Lagrangian, that off-diagonal elements of $A^{\prime} D A$ are zero, are satisfied anyway; $A^{\prime} \Omega A$ is the identity matrix, and we thus know that $A^{\prime} \Omega w \Omega A=\Lambda$. To maximize the trace of $A^{\prime} \Omega w \Omega A$ we select the $Q$ eigenvectors with the highest eigenvalues.

The matrices $A$ and $\beta$ are related by a couple of expressions. The matrix $A$ equals $-M w \beta^{\prime} \Lambda^{-1}$. To see this, note that expression (7) is $M w \Omega A=A \Lambda$, and use the fact that $\Omega A=\beta^{\prime}$. Hence, since $M$ is idempotent, $M A=A$. Let us define a $C \times C$ matrix $D$ equal to $I-u^{\prime} / C$. This is the matrix such that, for any vector $\boldsymbol{x}, D x$ is the vector $\boldsymbol{x}$ from which the mean of all the elements of $x$ have been subtracted, i.e., $D x$ is demeaned $x$. Note that $D$ is both idempotent and symmetric, with rank $C-1$. Note also that $D M=D$ and $M D=M$. It follows that, if $w=I$ as in the empirical work below, $\beta^{\prime}=-D A \Lambda$, which means that columns of $\beta^{\prime}$ are the same as columns of $A$, except that they are demeaned and rescaled by multiplying by minus the corresponding eigenvalue. To see that $\beta^{\prime}=-D A \Lambda$ in this case, note that since, when $w=I, A=-M \beta^{\prime} \Lambda^{-1}$, $D A=-D M \beta^{\prime} \Lambda^{-1}$; since $D M=D, D A=-D \beta^{\prime} \Lambda^{-1}$. Using the fact that $D \beta^{\prime}=\beta^{\prime}$, the result follows. Note also that $\beta=\beta D=\beta M$. Because of 
these relations, we can write the portfolio vectors in several different ways: $R=X A=(X M) A=(X M) D A$.

$I+A \beta$ is the $C \times C$ matrix whose $i j$ th element is the exposure, after hedging, of country $j$ to country $i$ 's risk. If we include all possible components (that is, setting $Q$ equal to $C-1$ ) so that the $(C-1)$ eigenvectors of $w^{.5} M^{\prime} \Omega M w^{5}$ are complete, then, using (8), we see that $M^{\prime} \Omega M$ $=\beta^{\prime} \beta$. Then it can be shown that, regardless of the weighting matrix $w$ chosen, $A \beta=-M$ and $I+A \beta=\iota \gamma$ where $\gamma$ is the vector of regression coefficients when each country's present value of real income is regressed on the present value of world real income, that is, $\gamma=\left(\iota^{\prime} \mathbf{R}_{\iota}\right)^{-1} \iota^{\prime} \Omega$. That $I+A \beta=\imath \gamma$ means that each country is holding a portfolio whose risk is the fitted value of its national income regressed on world income; everyone is completely diversified and subject to world income risk only. But such diversification does not generally occur unless we have $C-1$ markets.

To clarify what we have done, consider the case where the world consists of four countries, and that the first two countries are highly correlated with each other, but uncorrelated with the second two countries. Moreover, the second two countries are highly correlated with each other and all four countries have the same variance. Our $Q$ matrix is given by expression (9):

$$
\mathbf{\Omega}=\left[\begin{array}{cccc}
1.0 & 0.9 & 0 & 0 \\
0.9 & 1.0 & 0 & 0 \\
0 & 0 & 1.0 & 0.9 \\
0 & 0 & 0.9 & 1.0
\end{array}\right]
$$

Then, $M^{\prime} \Omega M$ has the form given by expression (10), 


$$
M^{\prime} \mathrm{Q} M=\left[\begin{array}{rrrr}
.525 & .425 & -.475 & -.475 \\
.425 & .525 & -.475 & -.475 \\
-.475 & -.475 & .525 & .425 \\
-.475 & -.475 & .425 & .525
\end{array}\right]
$$

which has one eigenvalue equal to 1.9 and two eigenvalues both equal to 0.1 . The vector $\boldsymbol{A}$, derived as shown above using the eigenvector corresponding to the largest eigenvalue is given by expression (11).

$$
A=.3627\left[\begin{array}{r}
-1 \\
-1 \\
1 \\
1
\end{array}\right]
$$

Thus, except for scaling, the component may be described as just a short position in the first two countries and an equal and opposite long position in the other two. This contract is, as we might expect, a swap between the two blocks of countries. This component is quite different from the first principal component of $\mathbf{Q}$. That matrix has two first principal components, both with the same eigenvalue. These components are proportional to the vectors $\left[\begin{array}{llll}1 & 1 & 0 & 0\end{array}\right]^{\prime}$ and $\left[\begin{array}{llll}0 & 0 & 1 & 1\end{array}\right]^{\prime} ;$; if we created a market in either of these, then we would not provide any means for the two groups of countries to swap their risks. The vector $\beta$ is given by expression (12).

$$
\beta=.6892\left[\begin{array}{llll}
1 & 1 & -1 & -1
\end{array}\right]
$$

The first two countries are short the component, the second two are long the component.

If we were to create the next two markets, then each of these markets would entail a swap between the pairs of countries within one block. The risk reduction afforded by such swaps is much smaller because the countries are so highly correlated within each pair. 
It is instructive to look at the matrix $I+A \beta$ whose $i$ th column gives the exposure of country $i$ to risks in each of the four countries after hedging in the one market, expression (13).

$$
I+A \beta=\left[\begin{array}{rrrr}
.75 & -.25 & .25 & .25 \\
-.25 & .75 & .25 & .25 \\
.25 & .25 & .75 & -.25 \\
.25 & .25 & -.25 & .75
\end{array}\right]
$$

Not all elements of this matrix equal .25 , as would be the case if we had included all three possible markets and thereby spanned the world risk sharing opportunities, resulting in each country's holding one quarter of the world. Since we have only one market for trading income, it is not possible for each country to hold the world income, but the holdings shown in expression (13) do nearly as well for risk reduction, given the covariance matrix $\Omega$ that was assumed. For example, for country 1 the holding of .75 times its own income minus .25 times country 2 's income is almost as good as the holding of .25 times its own income and .25 times country two's income, given the high correlation between the two.

Suppose, to pursue this example further, that we changed the weight matrix $w$ from the identity matrix to a matrix that gives much more weight to the first two countries, but keeping the weights constant within each country pair. This change in weights would have no effect on any of our optimal securities. Even if the contract designer cares primarily about the variance reduction of the first two countries, there is still nothing better that the market designer confined to one market can do for them than create a swap between this pair of countries and the other pair. And, if there is to be a second market, the best that can be done is to have a swap between the first two countries; if a third market, between the last two 
countries. If, on the other hand, the contract designer cares primarily about the first country, giving much more weight to it and equal weight to the other three countries, then the optimal first market will look very different; it will be approximately a swap between the first country and the rest of the world. Thus, giving unequal weight to countries that are in groupings within which countries are highly correlated with each other can break the grouping up for contract definition.

We note, finally, that with the pure variance reduction method there is a convenient way of measuring the importance of each market. We can regress the $c$ th country's national income on the $q$ th world income component, and take the variance of the fitted value in this simple regression, as the explained sum of squares for that country and market; this variance is just $\beta_{q c}^{2}$. Since all of the components are independent of each other, the sum of these variances $\left(\Sigma(q=1, \ldots, Q) \beta_{q c}^{2}\right)$ is the variance of the fitted value in a multiple regression on all of the components; if we add to this variance the variance of the residual in the regression, we get the total sum of squares, which is just $\operatorname{var}\left(X_{q}\right)$. In our empirical work below we will show for each market, as a measure of its importance, the explained sum of squares as a percent of the total sum of squares.

\section{A UTILITY MAXIMIZATION METHOD FOR DEFINING SECURITIES}

A problem with the assumptions that led to the above-defined income component securities is that it was assumed that no country could pay, in effect, an insurance premium to another country to assume some of its risk. In the above framework, if, let us suppose, there were one country whose national income had no risk at all, and another with high risk, there 
would be no opportunity for risk sharing between them. In this example and the pure variance reduction framework, the country with no uncertainty could achieve no further reductions in uncertainty, and so would not be interested in making any risk-sharing arrangements. In fact, however, it is logical that a country that had no risk could be induced to bear a little risk in exchange for an increase in the expected value of its income.

We now hypothesize that individuals in all countries share the same mean-variance utility function. We allow $P$, the vector of prices of the $Q$ securities arrived at at time 0 , to be nonzero. We derive the demand for each income component security by all countries, and derive the market clearing price. The contract designer, assumed to know the utility functions, chooses a number $Q$ of income component securities to maximize a weighted sum of the expected utilities, i.e., to maximize a social welfare function. Note the difference from the analysis of the preceding section, where the contract designer was required to find securities such that the markets would clear at a zero price for countries interested only in reducing variance.

The utility function that we hypothesize (the same for individuals in all countries) is:

$$
U_{c}=\sum_{t=1}^{T} u_{t c} /(1+p)^{t}
$$

where $u_{t c}$ is felicity, or instantaneous utility, of an individual in country $c$ at year $t$, and $\rho$ is the discount rate, i.e., subjective rate of time preference. The felicity $u_{t c}$ is defined by the function of mean and variance:

$$
u_{t c}=\text { constant }_{t c}+\frac{\bar{y}_{t c}}{\left(y_{0 c}(1+g)^{t}\right)^{\alpha}}-\frac{\alpha \operatorname{var}\left(y_{t c}\right)}{2\left(y_{0 c}(1+g)^{t}\right)^{(\alpha+1)}}
$$


where $\bar{y}_{t c}$ is the mean, the expectation conditional on information at year 0 (contract date) of country $c$ 's real per capisa income, and $\operatorname{var}\left(y_{t c}\right)$ is the variance conditional on information at year 0 of country $c$ 's real per capita income at year $t$. The term $y_{0 c}(1+g)^{\prime}$, where we take $y_{0 c}$ to be, for each country $c$, its 1990 per capita income (for the CIS, 1989 income) in US 1985 dollars, enters the expression for proper scaling of the mean and variance, taking account of the standard of living of the country. The coefficients chosen for the mean and variance of $y_{t c}$ may be motivated approximately as coming from a linearization of constant relative risk aversion felicity for an individual at time $t$ in country $c$, $u\left(y_{t c}\right)=\left(\left(y_{t c}\right)^{(1-\alpha)}-1\right) /(1-\alpha)$ around $y_{0 c}(1+g)^{b}$, where $\alpha$ is the ArrowPratt coefficient of relative risk aversion. Strictly speaking, the linearization of $\left(y_{t c}\right)$ would have an additional term, a deterministic term in $\left(\bar{y}_{t c}-y_{0 c}(1+g)^{t}\right)^{2}$. Including this term in the felicity function would destroy linearity of the demand functions, and thereby create large complications in our analysis; in any event if prices paid are not too large (as shares of national incomes) the term is small. For this reason, it is customary with the capital asset pricing model in finance to omit this term.

Let us define the $T \times C$ random matrix $X$ whose tcth element is real per capita national income $y_{s c}$ at year $t$ for country $c$ minus the expectation at year 0 (the date the contract is made) of this national income, times population in country $c$ in year 0 ; as above this is assumed to be national income accruing to population in year 0 who sign the contract. The $q$ th security is assumed to be a claim for each year $t=1, \ldots, T$ on income equal in amount to the tqth element of the linear combination $X \bar{A}$ of 
incomes. ${ }^{8}$ The vector $P$ has $q$ th element equal to the price of the $q$ th security. Note that these prices can be both positive or negative; in this sense they may be considered as analogous to the fixed schedule of cash transfers that are seen on certain swaps between risky assets; both sides of the contract are contractually committed to the contract; there is not free disposal, and so there is no problem with negative prices. There is, in fact, a fundamental arbitrariness in the sign of eigenvectors, and the sign of each element of $P$ depends on the choice made for the sign of the eigenvector; in our empirical results presented below we choose the sign to make all prices nonnegative.

For country $c$ at year $t$ we have that the hedging reduces expected income $\bar{x}_{t c}$ by the purchase price times the number of contracts, that is, by $\bar{\beta}_{c}^{\prime} P(1+g)^{t}$. The variance $\operatorname{var}\left(x_{t c}\right)$ of income after everyone hedges is

$$
\operatorname{var}\left(x_{t c}\right)=\mathbf{Q}_{t c c}+\bar{\beta}_{c}^{\prime} \bar{A}^{\prime} \Omega_{t} \bar{A} \bar{\beta}_{c}+2 \bar{\beta}_{c}^{\prime} \bar{A}^{\prime} \Omega_{t c}, \quad t=1, \ldots, T
$$

where $\boldsymbol{\Omega}_{t c c}$ is the $c$ th diagonal element of $\boldsymbol{\Omega}_{t}$ and $\boldsymbol{\Omega}_{t c}$ is the $c$ th column of $\mathbf{\Omega}_{t}$. Let us define $\mathbf{\Omega}$ for the utility maximization method as the discounted sum, using discount factor $h=1 /\left((1+\rho)(1+g)^{\alpha+1}\right)$, of the variance matrices for national incomes $t$ periods hence, $\boldsymbol{\Omega}=\Sigma(t=1, \ldots, T) h^{t} \mathbf{\Omega}_{r}$ Since, with demeaned $X, E_{0} X=0, \mathbf{\Omega}$ equals $E_{0}\left(X^{\prime} G X\right)$ where $G$ is a diagonal matrix whose $t$ th diagonal element is $\left((1+\rho)(1+g)^{\alpha+1}\right)^{-t}$. The normalization we choose for $\bar{A}$ is $\bar{A}^{\prime} \Omega \bar{A}=I$. To derive the demands for the securities by all individuals in country $c$, we convert our expressions for

\footnotetext{
${ }^{8}$ In this section on mean-variance utility, we use bars over symbols $A, M$, $\beta$ and $\gamma$ that will be compared with variables in the preceding section on pure variance reduction; for simplicity we omit bars over $R, S, w, X, \lambda_{g}, \Lambda$, and $D$ even though their values too may differ from those of corresponding symbols in the preceding section.
} 
mean and variance into per capita measures, substitute them into the mean-variance utility function, multiply by population, take the present value over $t=1, \ldots, T$, use this definition of $\mathbf{Q}$, and differentiate with respect to $\bar{\beta}_{c}$. The demand is then found to be:

$$
\bar{\beta}_{c}=-\bar{A}^{\prime} \Omega_{c}-P x_{0 c} \tilde{T} / \alpha
$$

where $\tilde{T}=\left(\nu-v^{T+1}\right) /(1-v)$ and $v=1 /\left((1+\rho)(1+g)^{\alpha-1}\right)$, so that $\tilde{T}$ is the present value of a $T$-year $\$ 1$ annuity discounted using discount factor $v$. Note that demand in market $q$ is not affected by prices in the other markets; this property of demand is a consequence of the fact that the dividends on the securities are constructed to be uncorrelated with each other, and of the mean-variance utility assumption. This demand curve implies that country $c$ will purchase more of the security the lower the price and the lower the country's covariance with the security. It will hold a positive quantity of a security at a positive price only if the covariance is sufficiently negative so that the security is providing enough risk reduction to the country to warrant paying the price. Note also that a country whose own income is riskless will hold negative quantities of all securities, that is, be a seller of securities, (since we are normalizing all securities to have nonnegative price). This means that in terms of these markets it is strictly in the insurance business, of accepting risk in return for an insurance premium.

Representing this demand function for all countries, using the matrix $\bar{\beta}$ whose $c$ th column is the demand for country $c$, we have:

$$
\bar{\beta}=-\bar{A}^{\prime} \mathbf{Q}-P_{\imath}^{\prime} x_{0} \bar{T} / \alpha
$$

where $x_{0}$ is a diagonal matrix whose $c$ th diagonal element is $x_{0 c}$.

The vector of prices $P$ is determined so that the total demands for the 
securities is zero, i.e., so that $\bar{\beta}_{t}=0$. Using this market-clearing condition and solving for the price vector $\boldsymbol{P}$ we find:

$$
P=-\alpha \bar{A}^{\prime} \Omega_{l}\left(\tilde{T}^{\prime} x_{0} l\right)^{-1}
$$

This means that the price of the ith security is the average, over all countries, of the (weighted present value, $t=1, \ldots, T$ ) covariance of that securities' linear combination of incomes with the incomes of the countries, divided by the average $x_{0 c}$, multiplied by $-\alpha$, and divided by $T$. A security whose dividend correlates positively with the average country's income will have a negative price, a security whose dividend correlates negatively with the average country's income will have a positive price; we are normalizing the contracts so that price will always be nonnegative, and so that no contract's dividend correlates positively with the average country's income. The price of the qth security is zero if the sum over the $C$ countries of the regression coefficients of country c's income on $R_{q}$ equals zero. ${ }^{9}$

A special case will help clarify the general equilibrium that we have just derived. Suppose that there are only two countries, that $\alpha=1$ and $T=1$. Suppose also that only the first country has any uncertainty; therefore, since $\bar{A}^{\prime} \mathbf{\Omega} \bar{A}=1$, the vector $\bar{A}$ must have first element equal to $\pm 1 / \sigma_{1}$ where $\sigma_{1}=\Omega_{i 1}^{5}$ (the other element is irrelevant, $\Omega_{22}$ is zero). Resolving the sign ambiguity with principal components, let us choose the minus sign so that price will be positive. It follows from expression (19) that $P=\sigma_{1} /\left(x_{01}+x_{02}\right)$. The amount of the security purchased by

\footnotetext{
${ }^{9}$ Note that the four-country example presented in the preceding section in connection with expression (9) applies bere with the utility maximization method too if all four countries have same $x_{0 c}$, since then $M=\bar{M}$. This is then an example where $P=0$ even in our utility maximization case.
} 
the first (risky) country is, from expression (18), $P x_{02}$; the amount purchased by the other country is of course the negative of this. After hedging, the risk is borne by the two countries in proportion to their incomes (at the point of linearization), so that the ratio of post-hedging standard deviation to income (at the point of linearization) is equalized across countries. The value in year $O$ of the "insurance premiums" that are paid is $\bar{\beta}_{1} P$ and total insurance premiums divided by the income of country two is $\left(\sigma_{1}^{2} / x_{01}^{2}\right) /\left(1+x_{02} / x_{01}\right)^{2}$. If the second (riskless) country is much smaller than the first, then the total value of the insurance premiums divided by national income of the second country will be large, approaching $\sigma_{1}^{2} / x_{01}^{2}$ as we decrease $x_{02}$ to zero, but the amount of risk shared will be small relative to the national income of the first country. This is as we might expect: there is no way that a large risky country can improve its situation very much if the only other country is very small, and it can make a big difference to the small country to accept a small part of the large country's risk. If the second (riskless) country is larger than the first, then the "insurance premium" will be small, approaching zero relative to either country's income as $x_{02}$ is increased to infinity, and thefirst country will get rid of almost all of its risk. This too is as we might expect: the risk suffered by the small country is easily borne by the larger country, and since the risk is small for the larger country it is willing to bear it for a small total value of insurance premiums.

Let us now consider the contract designer's problem, which is to define a small number $Q$ of securities so as to maximize a weighted sum of utilities, a sort of social welfare function. We assume that the 
contract designer wishes to choose $\bar{A}$ to maximize: ${ }^{10}$

$$
S=\sum_{c=1}^{c} w_{c} U_{c}
$$

where $w_{c}$ is the weight in the social welfare function on country $c$. Letting $w$ denote the $C \times C$ diagonal matrix whose $c$ th diagonal element is the weight given to the utility of country $c$, we can rewrite this socjal welfare function as:

$$
S=\text { constant }-\operatorname{tr}\left(w\left(\tilde{T} y_{0}^{-\alpha} \bar{\beta}^{\prime} P_{t}^{\prime}+\frac{\alpha}{2} y_{0}^{-\alpha} x_{0}^{-1}\left(\Omega+\bar{\beta}^{\prime} \bar{\beta}+2 \bar{\beta}^{\prime} \bar{A}^{\prime} \Omega\right)\right)\right)
$$

where $y_{0}$ is a $C \times C$ matrix whose $c$ th diagonal element, $c=1, \ldots, C$ is the real per capita income in country $c$ in year 0 and where the constant does not depend on $\bar{A}$. If one substitutes our expression for $\bar{\beta}$ and regroups, one finds that this expression reduces to:

$$
S=\text { constant }+(\alpha / 2) \operatorname{tr}\left(w y_{0}^{-\alpha} x_{0}^{-1} \bar{\beta}^{\prime} \bar{\beta}\right)
$$

Thus, to maximize the social welfare function one need only maximize $\operatorname{tr}\left(w y_{0}^{-\alpha} x_{0}^{-1} \bar{\beta}^{\prime} \bar{\beta}\right)$ with respect to $\bar{A}$ subject to the three constraints: $\bar{\beta}$ $=-\left(\bar{A}^{\prime} \mathbf{Q}+\tilde{T} P_{\imath}^{\prime} x_{0} / \alpha\right), P=-\alpha \bar{A}^{\prime} \boldsymbol{B}_{l}\left(\tilde{T}^{\prime} x_{0^{l}}\right)^{-1}$, and $\overline{A^{\prime}} \mathbf{\Omega} \bar{A}=1$. Substituting the second constraint into the first, we find that $\bar{\beta}^{\prime}=-\bar{A}^{\prime} \Omega \bar{M}$ where $\bar{M}$ is defined as $I-\mathfrak{l}\left(\mathfrak{l}^{\prime} x_{0} l\right)^{-1} \mathfrak{l}^{\prime} x_{0}$. The $C \times C$ matrix $\bar{M}$ is not the same as the

${ }^{10}$ In future research, we might represent the contract designer as also maximizing with respect to the time schedule of price payments, which we have here exogenously set as growing at rate $g$. Since we do not represent credit markets in our model, choosing the wrong time path for price payments in the contracts may make the contracts less effective. The paths through time $t, t=1, \ldots, T$ of the conditional variance matrix of income $D_{t}$ and of the expectation of future income $E_{0} X_{t}$ could be modelled, and the optimal time schedule of price payments would generally depend on these paths. 
matrix $M$ in the preceding section, though it too is idempotent, of rank $C-1$. Substituting $\bar{\beta}=-\bar{A}^{\prime} \Omega \bar{M}$ then into $\operatorname{tr}\left(w y_{0}^{-\alpha} x_{0}^{-1} \bar{\beta}^{\prime} \bar{\beta}\right)$, we find that we are left with the problem of maximizing $\operatorname{tr}\left(w y_{0}^{-\alpha} x_{0}^{-1} \overline{M^{\prime} \Omega} \bar{A} \bar{A}^{\prime} \Omega \bar{M}\right)$ $=\operatorname{tr}\left(\bar{A}^{\prime} \mathbf{\Omega} \bar{M} w y_{0}^{-\alpha} x_{0}^{-1} \bar{M}^{\prime} \mathbf{\Omega A}\right)$ subject to the single constraint that $\bar{A}^{\prime} \mathbf{\Omega} \bar{A}=I$.

To maximize we set up, as in the preceding section, the Lagrangian that represents the constraint that diagonal elements of $\overline{A^{\prime}} \Omega \bar{A}$ equal 1 , but that disregards the constraints that off-diagonal elements equal 0 :

$$
L=\operatorname{tr}\left(\bar{A}^{\prime} \mathbf{Q} \bar{M} w y_{0}^{-\alpha} x_{0}^{-1} \bar{M}^{\prime} \Omega \bar{A}\right)-\sum_{q=1}^{Q}\left(\bar{A}_{q}^{\prime} \mathbf{Q} \bar{A}_{q}-1\right) \lambda_{q}
$$

where $\lambda_{q}$ is the Langrange multiplier for the constraint that the $q$ th diagonal element of $\bar{A}^{\prime} \mathbf{D} \bar{A}$ equals 1 . Differentiating with respect to the matrix $\bar{A}$ and setting the derivative to zero, we find the first order condition:

$$
\mathbf{Q} \bar{M} w y_{0}^{-\alpha} x_{0}^{-1} \bar{M}^{\prime} \mathbf{\Omega} \bar{A}=\mathbf{Q} \bar{A} \Lambda
$$

where $\Lambda$ is a diagonal matrix whose $q$ th diagonal element is $\lambda_{q}$. Since $\bar{\beta}^{\prime}$ $=-\bar{M}^{\prime} \mathbf{D} \bar{A}$, this equation can be rewritten in terms of $\bar{\beta}$ :

$$
\bar{M}^{\prime} \boldsymbol{Q} \bar{M} w y_{0}^{-\alpha} x_{0}^{-1} \bar{\beta}^{\prime}=\bar{\beta}^{\prime} \Lambda
$$

from which it can be seen that $\left(w y_{0}^{-\alpha} x_{0}^{-1}\right)^{5} \bar{\beta}^{\prime}$ has columns proportional to eigenvectors of the matrix $\left(w y_{0}^{-\alpha} x_{0}^{-1}\right)^{5} \bar{M}^{\prime} \cap \bar{M}\left(w y_{0}^{-\alpha} x_{0}^{-1}\right)^{.5}$. Since this matrix is nonnegative definite symmetric, $\bar{\beta}^{\prime} w y_{0}^{-\alpha} x_{0}^{-1} \bar{\beta}^{\prime}$ is diagonal. Using $\bar{\beta}^{\prime}$ $=-\bar{M}^{\prime} Q \bar{A}$, we see that $\bar{A}^{\prime} \mathbf{Q} \bar{M} w y_{0}^{-\alpha} x_{0}^{-1} \bar{M}^{\prime} \mathbf{\Omega} \bar{A}$ is also diagonal. Premultiplying (24) by $\bar{A}^{\prime}$, we see that $\bar{A}^{\prime} \Omega \bar{M} w y_{0}^{-\alpha} x_{0}^{-1} \bar{M}^{\prime} \Omega \bar{A}=\bar{A}^{\prime} \mathbf{\Omega} \bar{A} \Lambda$, and so $\bar{A}^{\prime} \Omega \bar{A}$ is diagonal too, and the constraints omitted from the maximization problem above, that off-diagonal elements are zero, are satisfied anyway. It follows that $\bar{A}^{\prime} \mathbf{Q} \bar{M} w y_{0}^{-\alpha} x_{0}^{-1} \bar{M}^{\prime} \mathbf{\Omega} \bar{A}=\Lambda$. 
The matrix $\bar{M}^{\prime} \Omega \bar{M}$ is a sort of present value (using discount factor $h$ $=1 /\left((1+\rho)(1+g)^{\alpha+\zeta}\right)$ of the variance matrices $t=1, \ldots, T$ of the vector of national incomes minus their corresponding shares of world income. For country $c$, the excess national income is computed as that country's national income minus its share of world income, the latter defined as $\bar{\gamma}_{c}$ $=x_{0 d} /\left(c^{\prime} x_{0} l\right)$, so that the share is determined in terms of our point of linearization, here 1990 real per capita GDPs. This is in contrast to the preceding section, where $M^{\prime} \Omega M$ was the variance matrix of present values $(t=1, \ldots, T)$ of residuals of real per capita national incomes regressed on the present value $(t=1, \ldots, T)$ of world real per capita incomes.

We now show that all of our contracts designed by the utility maximization method will be essentially swaps. First note that as in the preceding section, the matrices $\bar{A}$ and $\bar{\beta}$ are related by a couple of expressions. Premultiplying (24) by $\Omega^{-1}$ and using $\bar{B}=-\bar{A}^{\prime} \Omega \bar{M}$, we see that the matrix $\bar{A}$ equals $-\bar{M} w y_{0}^{-\alpha} x_{0}^{-1} \bar{\beta}^{\prime} \Lambda^{-1}$. Hence, since $\bar{M}$ is idempotent, $\bar{M} \bar{A}=\bar{A}$. It follows, since $\iota^{\prime} x_{0} \bar{M}=0$, that $\iota^{\prime} x_{0} \bar{A}=0$. This means that the sum of the contract shares of national incomes times the corresponding base-year income will be zero. We cannot have a situation in which all elements of a column of $\bar{A}$ are positive, as was a possibility with the $A$ matrix defined from the pure variance reduction method.

Note that $D \bar{M}=D$, where $D=I-u^{\prime} / c$ is as above. Note also that $\bar{\beta}=\bar{\beta} D=\bar{\beta} \bar{M}$. Because of these relations, we can write the portfolio vectors in several different ways: $R=X \bar{A}=(X \bar{M}) \bar{A}=(X \bar{M}) \bar{D} \bar{A}$. In words, it does not matter whether the data that are used to construct the dividends are first corrected by subtracting from each country its share of world income or if in this case the $\bar{A}$ is also demeaned by column.

We can now produce measures that place a dollar value on the avail- 
ability of these income component securities; given our mean variance utility function, these measures might be called either consumer surplus or equivalent variation or compensating variation; with mean-variance utility the measures are identical. For each of the $Q$ securities and each of the $C$ countries we can calculate the value in time 0 dollars of the utility change, by calculating what decrement in time 0 income would just offset the utility increase. Putting it another way, we can calculate, in $\bar{\beta}_{q c}-P_{q}$ space, the area of the triangle bounded by the equilibrium price $P_{q}$, the line $\bar{\beta}_{q c}=0$ and the linear demand curve given by equation (18). Note that this consumer surplus includes both the value of the variance reduction caused by the hedging and the value of the price received (if the country was a net seller of securities, as when the country was serving as an insurer of other countries' risks). The $Q \times C$ matrix $F$ whose $q c$ th element is total dollar value of the utility gained by using market $q$ by country $c$ as a fraction of GDP $\left(x_{0 c}\right)$ is given by:

$$
F=\frac{\alpha}{2}\left(\beta X_{0}^{-1}\right)^{2}
$$

where the exponentiation is element-by-element, that is, for country $c$ and income component security $q$, the consumer surplus is just $(\alpha /(2))\left(\bar{\beta}_{q c} / x_{0 c c}\right)^{2}$. Note that this expression gives us the total dollar present value of felicity gains in all future periods $t=1, \ldots, T$ as a fraction of expected income in the base year only; to convert this to a fraction of GDP paid each year $t=1, \ldots, T$ one would have to divide by $\tau^{11}$ Note also that the weighted sum, weighted using the weights for

\footnotetext{
${ }^{11}$ For example, in our Tables II and III below, when $T=40$, one would divide by $T=11.48$. Such a calculation would give that constant fraction of income that would be deducted each period $t=1, \ldots, T$ to just offset the
} 
each country given by the matrix $w$, of all the elements of the matrix $F$ defined in expression (26) equals the expression maximized above, $\operatorname{tr}\left(\bar{A}^{\prime} \Omega \bar{M} w y_{0}^{-\alpha} x_{0}^{-1} \bar{M}^{\prime} \Omega \bar{A}\right)$, see expression (23), times a constant. The first market thus maximizes the weighted sum of the consumer surpluses divided by national incomes for one market, the second the weighted sum of the consumer surpluses divided by national incomes for the second market, and so on. Thus, of course, when we choose $w$ as something other than $y_{0}^{\alpha} x_{0}^{-1}$, thereby choosing to maximize a weighted sum, not the simple sum, of consumer surpluses divided by national incomes, our apparent success in generating consumer surplus by creating only a few markets, to someone viewing a table presenting a matrix $F$ such as appears below, will not be as high as it could be.

\section{DATA ANALYSIS}

Time series plots of the ten-year growth rates of real per-capita GDP series for the ten largest countries for which we have GDP data 19501990 are shown in Figure 1. It is immediately apparent that there has been a lot of variability of these growth rates for certain countries. In Japan, the growth rates have varied from $26 \% \%$ to $153 \%$. In Brazil, they have ranged from $-8 \%$ to nearly $99 \%$. Plainly, changes in income of these magnitudes over ten-year intervals matter a lot to those receiving the income, and sharing the risk of such changes would have proven very

overall utility gain from creating the new markets. Because of the heavy discounting in our Table II and III results, this fraction would tend to be far below the value of felicity gained as a fraction of income in that year for years near the end, near year $T$. 
beneficial to these people. These fluctuations in GDPs are very real; this is in contrast to the earthquakes or meteor impacts that theoretical economists often tell stories about, but which appear never in history to have caused economic dislocations that were remotely as big.

It is also apparent that the different countries have substantially different income growth paths through time, and that there is no simple shared pattern to the growth paths that would inspire confidence that we know how to forecast them far out. It is also apparent from the plots that there is a tendency for neighboring countries to be substantially positively correlated with each other, and that distant countries may be uncorrelated or even negatively correlated with each other. Some correlations are estimated to be negative: India and Japan happen to show large negative correlation over this period. Because there is not much information about correlations in these data, which are dominated by low-frequency movements and for which we have no secure model, we cannot attach much confidence that national incomes in these countries really tend to move opposite each other.

For our analysis, we must convert these general impressions into some estimates of the matrices $\mathbb{\Omega}$. Estimating the variance matrices is not a trivial matter; these are supposed to reflect the conditional variance at the time of the contract for distant future national incomes. To estimate such a variance matrix, we need first to form some representation of the conditional expected value each year for all future national incomes, a problem that the world's macroeconomic forecasters have been spending decades to develop.

There are very many models that might be used to provide estimates of $\mathbf{\Omega}$. Estimating time series models, such as autoregressive models, for 
the national income of each country would help us to separate out which components of national incomes are forecastable and which are not. There is, however, a risk inherent in specifying any simple autoregressive model, that it will not capture accurately the long-term risks that we want to hedge. Estimating spatial models, such as the spatial autoregressive models or other Markov random field models, would allow us to put structure on the matrix $\mathbf{\Omega}$ so that fewer parameters would be estimated, so that our shortage of information about long-run risks would present less of an estimation problem. Spatial models could use sophisticated concepts of economic distance between countries, or prior information about the similarity of different countries. There is a risk in any spatial model specification, though, that we may be using the wrong measure of economic distance between countries, and therefore impose incorrect priors or restrictions on our variance matrices.

It is beyond the scope of this paper to set forth a definitive treatise on how to estimate $\Omega$; we leave that for possible future work. For this paper we used two very simple methods to estimate, methods that appear to be transparent and fairly robust to many kinds of possible misspecification, with the hope that our estimates will be at least suggestive of the new markets that may be created. Our methods of producing the $\mathbf{\Omega}$ matrices will at least capture in some fashion the magnitude of variability of national incomes, the tendency for much of this variability to be idiosyncratic, and the tendency for some measure of comovement across countries, even if the estimated matrices are not highly accurate. At this stage in our research, we approach the problem in almost the same spirit that real business cycle modelers have who "calibrate" their models. We are hoping to tell a simple story that has an important element of truth in 
it, and are not now particularly interested in testing our variance matrix model against general alternatives; even if the model were rejected the estimated $\mathbf{n}$ may yet be useful for our purposes.

Our two methods of estimating $\mathbf{Q}$ differ in what they assume about the representativeness of past historical movements for the future. Our Method A, which involves estimating simple unconstrained variance matrices from historical data, makes no assumptions about similarities of or economic distances between countries. This method, since it requires a lot of data, is used only for a rather low $T$, equal to ten years; even with this low $T$, we do not expect to get accurate estimates of variances. ${ }^{12}$ Our Method B, which involves estimating constrained variance matrices, imposes some strong priors and thereby saves degrees of freedom so that we have better prospects of estimating variance matrices with high $T$; with Method B we use $T$ equal to forty years. Neither method makes use of time series models to infer conditional moments; both are based on the assumption that conditional variances of long-horizon changes in income are best estimated directly as moments of long-horizon changes themselves. Our motivation is the

\footnotetext{
${ }^{12}$ We have only four nonoverlapping time intervals with which to compute variances of ten-year present values. Supposing that the variables are normal and independent across the four time intervals, and approximating our variance as estimated from four such observations, then the variance estimate will be proportional to a $\chi^{2}$ variate with three degrees of freedom, and an $80 \%$ confidence interval for a standard deviation is from $80 \%$ of the estimated standard deviation to $262 \%$ of the estimated standard deviation. We have not tried to produce standard errors for our variance matrices, since such standard errors would depend on the assumed model for our processes and there are many possible models to which we at this point attach prior probability. Further refinement of our knowledge about $\mathbf{\Omega}$ is left to later work.
} 
notion, based on our reading of other's success in forecasting, that tenor forty-year changes in national incomes are virtually unforecastable.

Method A. For the pure-variance-reduction calculations, to estimate $\mathbf{Q}$, we take the sample variance matrix for the $C$ countries of GDP $_{1990}$ $\times\left(\Sigma(i=1, \ldots, T) \mathrm{gdp}_{t+i} /\left((1+\rho)^{i} \mathrm{gdp}_{t}\right)\right.$ with sample period $t=1950, \ldots$, 1990-T, 41-T observations, where GDP denotes total, not per capita, gross domestic product in 1990 (in 1985 dollars), and gdp denotes real per capita gross domestic product in year $t$ (in 1985 dollars). For the utilitymaximizing case, to estimate $\Omega_{i}, i=1, \ldots, 10$, we take the sample variance matrix for the $C$ countries of $\mathrm{GDP}_{1990} \times\left(\mathrm{gdp}_{t+i} / \mathrm{gdp}_{t}\right)$ with sample period $t=1950, \ldots, 1990-i, 41-i$ observations. We then form our estimated $\Pi$ as $\Sigma(t=1, \ldots, I) \Omega_{t} /\left((1+\rho)(1+g)^{\alpha+1}\right)^{t}$.

Method B. With this our second method of estimating $\mathbf{\Omega}$, we impose prior restrictions that all countries have the same mean and variance of percentage changes in real per capita income, and that covariances are determined solely by the geographic distances between countries. The motivation for requiring that all countries have the same mean and variance of percentage changes of real per capita income is some skepticism that the past exigencies that faced particular countries $1950-90$ can really be expected to repeat in those same countries in the future. Our figures show that Japan has had much higher growth rates than most of the other countries. Do we really have reason to expect that growth rates will be similarly higher in the future in Japan? Our figures suggest that Japan and Brazil are risky countries. Do we really have any reason to think that these countries will be the ones facing the greatest risks in the future? Perhaps they are just buffeted by some major crises in this sample, crises the likes of which may just as well strike other countries in the future. 
The motivation for requiring that the correlation across countries in changes in real per capita income depends only on the distance between the countries is much the same, we do not really attach much credence to the suggestion of simple variance matrices computed by Method $A$ that India and Japan should be expected to be negatively correlated in the future.

Our prior assumptions for Method B about the variance matrix $V$ of $T$-year percentage changes in real per capita national incomes are represented by the formula:

$$
\ln \left(V_{i j}\right)=a-b d_{i j}, \quad b \geq 0
$$

where $d_{i j}$ is the distance between countries $i$ and $j$, measured as air miles between the major city in the respective countries. We used the air mile distances between the major cities Montreal, Mexico City, New York, Rio de Janeiro, Calcutta, Tokyo, Paris, Berlin, Rome, London, Shanghai, and Moscow. Since $b$ is positive, the further away the major city, the less is the covariance with its country. This formula corresponds to a valid (i.e, the variance matrix is nonnegative definite for any placement of cities) isotropic (i.e., the model is invariant to rotations of the coordinate system) spatial model where the cities lie in $\mathbf{R}^{2}$, see Cressie $(1991$, p. 86 ). The formula also corresponds to a valid isotropic spatial model where the cities lie on the surface of a sphere and distances are measured along great circles, as in our application to the earth. Moreover, the variance matrix is strictly positive definite unless two cities coincide.

This formulation restricts all covariances to be positive. The prior restriction that all covariances are positive may seem strong, but it is maintained here as a sort of common sense prior notion that there is really no reason in general for any pairs of countries to tend to move opposite 
each other. This restriction may serve to reduce the possibilities for diversification, by eliminating the negative correlations that diversifiers seek.

Our assumption that the variance of the percentage change in incomes is the same in all countries reflects an underlying assumption that people within countries share a country risk common to them all, so that national borders have some economic signicance, and are not just random closed curves on a map. If national borders had no economic significance, then we might expect that larger countries would have smaller variances of percentage changes, since there would be more opportunity for geographical diversification within the larger countries. This assumption of constant percentage change variances will be important to some of our results, since it implies that diagonal elements of $\mathbf{Q}$ are related to $x_{0}^{2}$ rather than to $x_{0}$.

For the pure variance reduction case, we compute the constrained maximum likelihood (multivariate normal) variance matrix $V$ for the 10 countries of $z_{c}=\Sigma(\mathrm{i}=1, \ldots, \eta) \mathrm{gdp}_{1990} /\left(\operatorname{gdp}_{1990-i}(1+\rho)^{\prime}\right), c=1$, $\ldots, 10$; there is only one observation of $z_{c}$ for each country, but there are only three unknown parameters of the utility function, $a, b$, and the mean growth rate. Using the estimated parameters, $a$, and $b$, and the mean growth rate, and then using distance data and real national income data for China and the CIS (the latter including the Baltic countries, so that it corresponds to the former Soviet Union), we construct using (27) a twelve by twelve $V$ matrix for the twelve countries, and using the Summers-Heston data for real GDP for all countries in 1990, we construct a twelve by twelve $X_{0}$ matrix for all twelve countries. Then we take $\mathbf{\Omega}=$ $X_{0} V X_{0}$. For the utility-maximizing case, to estimate $V_{i}, i=1, \ldots, 40$, we take the maximum likelihood variance matrix for the 10 countries of 
( $\left.\mathrm{gdp}_{1990} / \mathrm{gdp}_{1990-i}\right)$, one observation for each country. We construct the forty twelve by twelve $V_{l}$ matrices as we did in the pure variance reduction case, and the resulting forty variance matrices are each multiplied by $\left.\left((1+\rho)^{-i}(1+g)^{-(\alpha+1) i}\right)\right)$ and summed to produce our estimate of $V ; \Omega$ is then taken to be $X_{0} V X_{0}$.

Note that the maximum likelihood method will tend to produce downwardly biased estimates of variance, since with only one observation for each country, the estimated mean will tend to pick up the component of the variation that is shared by all countries; recall that in the iid case the maximum likelihood estimate of variance is sum of squared residuals divided by $N$ rather than $N-1$. The downward bias will be more severe here than in the iid case, since our countries are positively correlated with each other by assumption. Still, the maximum likelihood estimate is the posterior mode based on uninformative priors, and we think that this conservative estimate of variance is acceptable for our purposes.

Our methods also require that we specify a weighting matrix $w$ for our maximization problems that define the contract weights, that are represented in the matrices $\boldsymbol{A}$ and $\bar{A}$. In our pure variance reduction method, we take the matrix $w$ to be the identity matrix $I$ : we are merely minimizing total variance. This weighting matrix preserves a simple correspondence between our method and principal components analysis. In our utility maximizing approach, we use two different $w$ matrices. One of these is $w=y_{0}^{\alpha} x_{0}$; this matrix gives most weight to the large countries in terms of real gross domestic product. We used this matrix because we think that large wealthy countries provide more fertile ground for establishing innovative new markets; we want the benefits of the new markets to be large there. Moreover, with $w=y_{0}^{\alpha} x_{0}$ the $w$ matrix and the $y_{0}^{-\alpha} x_{0}^{-1}$ 
matrix cancel in the matrix whose eigenvectors we take, making for the closest parallel with the pure variance reduction method here. The other $w$ we will use for the utility maximization method is the identity matrix $I$. This allows our method to downweight the people in wealthier countries, effectively since their marginal utilities of income are lower than with those in the poorer countries; they tend to benefit less from risk management. This weighting scheme is implied by our interpretation of our mean-variance utility function as a linearization of a constant-relative-riskaversion utility function with coefficient of relative risk aversion, $\alpha$. This choice of weights will mean that should two countries, identical in terms of per capita income, be lumped together, then our analysis would yield the same results as if the two countries were treated separately; we are really maximizing the total utility of individuals, under the assumption that individuals within each country are identical.

We must finally specify the anticipated growth rate $g$, the risk aversion parameter $\alpha$, and the discount rate $\rho$ for our analysis. We took $g$ equal to the average real per capita growth rate of all ten countries from 1950 to 1990, 3.07\% per year (except in Table IV). Empirical studies have found wildly different estimates of risk aversion parameter $\alpha$ and the discount rate $\rho$, depending on the kind of circumstances that generate the data, see Thaler (1990). Values of $\alpha$ have been estimated in the 100s, but these may be regarded as implausibly high; we chose $\alpha$ equal to three as representing a sort of consensus by many who work in this literature as a reasonable value to assume. We believe that the high discount rates that are sometimes estimated are evidence of judgmental errors that people often make, rather than true preferences. As Pigou (1934) argued long ago, people appear to have a "telescopic faculty" that is defective, causing 
them sometimes to underestimate the importance of the future. We assume that on decisions as important as bedging the standard of living, people will behave more rationally, and use a rather low discount rates, which we have set at $2 \%$.

In an important sense, our choice of $g, \alpha$, and $\rho$ imply implausibly high discounting. The figures we have specified would imply, using the constant relative risk aversion utility function, that the risk-free real interest rate would be $(1+\rho)(1+g)^{\alpha}-1$, or $11.7 \%$ per year, far above historical averages. This implausibly high implied risk-free rate is part of the equity-premium puzzle presented by Mehra and Prescott (1985). There does not appear to be any agreed-upon way to deal with this puzzle; we have dealt with this problem only in a rough way by presenting one last table that substitutes an expected growth rate $g$ of zero in place of the $3.07 \%$ used in the other tables, so that the puzzle is resolved by supposing that people do not expect past growth rates to continue.

\section{RESULTS}

We present results (with $Q=2$, two markets and the parameter values described above) for the pure variance reduction method and $w=I$, Table I; for the utility maximization method and $w=y_{0}^{\alpha} x_{0}$, Table II; and for the utility maximization method with $w=I$, Table III. Finally, we present utility maximization results using $w=y_{0}^{\alpha} x_{0}$ where the growth rate $g$ is set to zero, Table IV. In each table, the results are presented first for variance matrix estimation method $A$ (unconstrained) and ten countries, and second for variance matrix estimation method $B$ (constrained) and twelve countries. 
The estimated $\mathbf{n}$ matrices (not shown), whether constrained or unconstrained, show that near neighbors tend to have higher correlations than do more distant countries. ${ }^{13}$ With the unconstrained variance matrices, covariances are usually positive with the exception of India, whose covariance is estimated to be negative with most other countries. With the constrained variance matrix estimates, all covariances are constrained to be positive. For the pure variance reduction case and constrained variance matrix estimate, corresponding to Table I panel B, the estimated correlation between (forty-year present values of income in) the US and Canada is 0.88 , between France and Germany is 0.80 , between China and Japan 0.65 . The estimated correlation between distant countries is quite small: the correlation between the US and Japan is 0.07 , between the US and the CIS is 0.16 , between the CIS and China is 0.19 . India of course no longer has negative correlation with anyone: its correlation with China is estimated at 0.43 , with Japan, 0.28 , with the United States, 0.04 . The pattern of correlations is similar in the utility maximization case, panels $B$ of Tables II, III and IV.

The optimal contracts shown in these tables are difficult to summarize. The contract definitions involve all countries, with varying weights, and so there is no simple way to describe them accurately in a few words. Moreover, the positions that countries take in these contracts are not the same as their weights in the contract definitions. In Table I where $\beta^{\prime}$ is proportional to a matrix of eigenvectors of $M^{\prime} \Omega M$ and Table II and Table IV where $\bar{\beta}$ is proportional to an eigenvector of $\bar{M}^{\prime} \Omega \bar{M}$, the columns of $\beta^{\prime}$ and $\overline{\boldsymbol{B}}^{\prime}$ are proportional to demeaned columns of $-\boldsymbol{A}$ and $-\bar{A}$ respectively.

\footnotetext{
${ }^{13} \mathrm{An}$ appendix showing detailed results is available from the authors.
} 
In these tables, therefore, the positions of most countries have the opposite sign of the corresponding weights in the contract definition, though this is not true for all countries whose contract weight is near the mean weight across countries in that market. In Table III, the relation between contract weights and positions is much less clear: countries with little weight in the contract definition sometimes taking large positions, countries with large weight in the contract definition taking small positions.

Let us make some broad generalizations about these contracts in terms of the contract weights, that is, in terms of the columns of $A$ and $\bar{A}$. In Tables I, II and IV, where large wealthy countries dominate in determining our results, the first contract can be described in rough terms as approximately a swap between US and the Far East (in panels A, the Far East is represented only by Japan, in panels B by Japan and China), though in Table I panel A Germany also plays an important role. The second market in Tables I, II and IV is less easily described. In panels B, where we have added China and the CIS, the second market might be described in simple terms as a swap between the European community and CIS on one side, and China, Japan and the US on the other. In panels A of Tables I, II and IV, however, the swaps tend to put a lot of weight on Brazil. In Table III, where the utilities are unweighted, so that poorer countries become more important, the first market tends to be approximately a swap between the poorest country (in per capita income) and the rest of the world, the second market a swap between the second-poorest country and the rest of the world.

Part of these results can be understood in terms just of the scale of the individual countries, to the extent that covariances are not of dominant importance. Scale can be measured in different ways, either in terms of 
the variance of the national income, or in terms of the per capita income, or in terms of the population. Scale as measured by variance is useful in understanding the unconstrained variance matrix results with ten countries (Panels A). Japan has the highest variance of present value of national income, the US the second highest, and Brazil the third highest. (The United States is a low estimated variance country in terms of percentage changes in GDP, but it makes up for this in terms of sheer size, making our measured uncertainty about United States GDP the second largest of the ten.) Per capita income and sheer population matters greatly in our unweighted utility maximization results, Table III. India matters vastly more than any other country: it had a 1990 population over three times that of the next most populous country (the United States) in our list of ten countries and a per capita income only a little over a quarter that of the next-poorest of our ten countries, Brazil. The first market is obviously a swap of India's national income for the rest of the world's income; all the countries other than India have virtually the same coefficient in the first column of the $\bar{A}$ matrix; in this sense the contract is plainly designed for India's benefit. The market benefits India substantially, both in terms of the variance reduction it permits for India and from the price it receives for selling contracts, starting at a real $\$ 48.17$ (in 1985 dollars, Table III panel A) for the first year for each contract, amounting to a real $\$ 13.47$ per person in India, and growing at $3.07 \%$ per year thereafter.

Note that with these utility maximization method results using a $w$ matrix that gives so much weight to one poor country, the ratio of weights $A_{\text {(other country) } 1} / A_{(\text {India)l }}$ for the first security are very nearly $a /(1-a)$ where $a$ is India's share in world income as measured by our $x_{0}$ matrix. It might seem obvious that a contract that was expressly designed for India should 
be a swap of India's national income for the world. But it should be remembered that our contract design method took into account the willingness of other countries to take the other side of India's positions, and the benefit to India of the price received. One might have thought that the other side of the swap would not be equal shares in all national incomes (which gives smaller countries less impact on the swap regardless of their covariance with other countries) but instead some variance-minimizing portfolio of national incomes. One might have thought that with our unconstrained variance matrix results, Table III panel A, India might have been even better off if we left the Japan component of world income out of the swap, since with our unconstrained variance matrix estimate Japanese national income is extremely volatile, and India winds up bearing some of the risk of Japanese national income. But, if we left Japan out of the swap, then India would not receive such a good price for selling the contracts. Note that India does not pay anything at all for this insurance of its national income risk, but profits from it. Japan uses this India/restof-the-world swap to reduce the variance of its own income, since Japanese income uncertainty is fairly dominant part of the uncertainty represented in this swap, even though the weight given to Japan is small. Even though Japan was given very little weight by our contract designer, in consumer surplus terms, in Table III panel A, Japan benefits almost as much as India does from this contract, and Japan buys (according to the first column of the $\overline{\boldsymbol{\beta}}^{\prime}$ matrix) nearly twice as many contracts as India sells. Japan benefits especially much because Japan's income is, in our unconstrained variance matrix estimate, negatively correlated with India's income. Other contracts that Japan buys are provided largely by the United States, who sells nearly as many contracts as India does the US 
accepting thereby a $42.30 \%$ increase in its small real per-capita income variance), accepting some Japanese income risk in exchange for the real $\$ 48.17$ per contract. Japanese real per capita income variance is reduced $51.68 \%$ by this one contract; Japan is able to reduce its variance dramatically more than the $2.75 \%$ in the pure variance reduction case because it pays other countries to take on its risk. Fortunately Japan does not need to pay very much for this variance reduction, only $1.08 \%$ of Japanese 1990 GDP. Even though the first column of the $\bar{A}$ matrix seems to give little weight to Japan, still, given the small estimated diagonal element of Q corresponding to India (only $3.79 \%$ of the element corresponding to Japan) and the negative correlation of India with Japan, this contract may actually be viewed, in variance reduction terms, as more nearly a riskmanagement contract for Japan, than one for India. India reduces its real per capita income variance by $43.69 \%$ with this contract, a smaller percentage reduction than Japan achieves.

One might have thought that China would show more importance than India in the Table III panel B utility maximization results, since it has a larger poor population. However, its population in 1990 was only $36 \%$ larger than India's in 1990, and, offsetting this, its Summers-Heston real per capita income in India was only $45 \%$ that of China. Note that neither of the markets in Table III panel B could be interpreted as designed for Brazil, as was the second market in the Table III panel A utility maximization method results. The inclusion of China for Table III panel B calculations, a country with only $60 \%$ the real per capita income and over seven times the population of Brazil in 1990, has bumped the market most important to Brazil to the third market (not shown in Table III panel B). The CIS, which, while its population was nearly twice that of Brazil, had 
nearly $40 \%$ higher real per capita income in 1990; has to deal in the fourth market (also not shown in Table III panel B) for its largest benefits.

To help understand the sometimes great difference between the columns of the $\bar{A}$ matrix and the columns of the $-\bar{\beta}^{\prime}$ matrix, consider the puzzle that in Table III panel B the second contract appears by the weights $\overline{\boldsymbol{A}}_{c 2}$ that define this contract to be roughly an India/China swap, yet India sells (as shown by the positions $\bar{\beta}_{2 c}$ ) almost none of this contract, and produces from this sale the smallest consumer surplus of any country in the world. One might think that a contract designer would want to leave India out of this contract altogether; it would appear that India is just adding extraneous noise to a contract that would otherwise be a China/restof-the-world swap. In fact, however, the benefit that India receives from this contract is important to our contract designer given the great weight that India receives in our social welfare function. Note that contract 1 (defined by the weights $\bar{A}_{c l}$ ) did not work out to be exactly an India/restof-the-world swap, since China was underrepresented in it. China was given sufficient weight in our social welfare function that it was treated differently from other countries in the first contract. With two contracts, India is now able to achieve an accurate swap of her income with all the world's income, since $\bar{A} \cdot \bar{\beta}_{15}+\bar{A}_{2} \cdot \bar{\beta}_{25}$ is very nearly such a swap, the discrepant weight on China standing corrected. China, using the first two markets together achieves (with $\bar{A}_{\cdot 1} \bar{\beta}_{111}+\bar{A}_{\cdot 2} \bar{\beta}_{211}$ ) nearly a swap with world income too, except that India is overrepresented in the swap, a fact that is not too damaging to China given the relatively small contribution that India makes to the variance of the swap.

To help understand the explained sum of squares over total sum of 
squares, consider the first market of Table I, panel A. The explained sum of squares over total sum of squares is $47.42 \%$ for the United States, indicating that this one security makes it possible for the United States to get rid of nearly half of its uncertainty about income, but it offers much less benefit for Japan as a percent of its variance. Japan derives less benefit since its GDP variance is estimated to be three times higher than that of the next highest country, the US, and its income is substantially positively correlated with the US; there is in essence no one who benefits from taking on much of the Japanese risk. Japan has essentially exhausted most of its opportunities to lay off income risk; no one else has much risk to swap relative to Japan's. To understand this, note that the $R^{2}$ when Japan's present value of real per capita income is regressed on world present value of real per capita income as measured here is nearly ninety percent (given the substantial size of the Japanese economy in the world and positive correlation with most countries in the world), so Japan has achieved nearly all the possible variance reduction with these two markets. In other words, with our unconstrained variance matrix estimate, most of Japanese risk is market risk which is undiversifiable.

To help understand the consumer surplus figures, note that, from equation (17), which defines $\bar{\beta}_{c}$ for any given country $c$, for any country whose real per capita national income is uncorrelated with $R_{q}, \bar{\beta}_{q c} / X_{0 c c}$ $=-\tilde{T} P_{q} / \alpha$; all such countries have the same consumer surplus as a fraction of base-year income given by (26). How great this consumer surplus is depends on $\boldsymbol{P}_{q}$; if the absolute value of $\boldsymbol{P}_{q}$ is small, there would be little benefit, i.e., little profit from insuring other countries against their risks. For a country for which real per capita national income covaries (positively or negatively) with $R_{q}$, the consumer surplus is greater if the 
covariance has the same sign as $\boldsymbol{P}_{\boldsymbol{q}}$. If the covariance is of the opposite sign, there could even be no benefit at all to this country from trading in the market; the benefit the country might obtain from receiving an insurance premium for taking on other countries' risks could be wiped out, given the covariances, by the extra increased own variance caused by doing that. Thus, it is clear why the US benefits so little from its large position in the first market with the utility maximization contracts, Table III panel A; for the US price works opposite variance reduction; in this case the US gained on price but lost on variance. Our results with India in the first market were the opposite of this case: India's real per capita income correlates positively with $R_{1}$ and the price $P_{1}$ is also positive.

A major factor tending to keep consumer surpluses down overall is the discounting in our calculations of the variance matrix $\mathbf{\Omega}$ caused by our assumed growth rate $g$ of $3.07 \%$ per annum for real per capita incomes. The high historical growth rate means that marginal utilities of future income are lower, and so the uncertainty about the distant future matters much less today. If we alter Table II by substituting a growth rate of $g=0$ in place of the $g=3.07 \%$ suggested by recent history, making, as discussed above, our implied risk-free rate come more in alignment with historical averages, then our consumer surplus figures increase dramatically; in Table IV panel B consumer surplus is increased by at least an order of magnitude, sometimes more nearly two orders of magnitude, when compared with Table II panel B. The Table IV results show that there is a possibility that consumer surplus may be dramatically higher than we have estimated with our other tables, given our lack of certainty that we want to extrapolate the growth trends of the last forty years into the next forty. 


\section{DISCUSSION}

Let us concentrate first on the Table II Panel B results that were derived under the premise that the contract designer wishes to maximize utility over a long time span and gives a lot of weight to the big countries. We concentrate on these results since, to manage standard-of-living risks, such long term contracts are very important for most people, and since such big wealthy countries appear to be the more fertile grounds for the establishment of major new markets.

The best first market to set up was found to be approximately a swap between the US, on one side, and the Far East (Japan and China) on the other. In looking at this result, one may feel that there is a sort of intuitive sense to it, that some of the biggest economies should share their income risk. Still, one may wonder why the arrangement took just this form in our results, and what is it about the estimated variance matrix that led our methods to this form. One might have thought that the methods would have led us first to a swap between the US, the biggest economy of the world, on one side, and the rest of the world on the other, with the risk shared equally among the other countries of the world; indeed that is just the first contract we would have found had we given much more weight (in our $w$ matrix) to the United States than to any other country. But taking a position in such a swap would not be as beneficial to the other countries of the world, since most would not achieve variance reduction in their own incomes by taking the other side of such a swap, each of them being a small part of the swap defined by the contract. The United States would have to pay them a substantial amount to make them willing to take on this risk, a payment that would compensate them for 
accepting the increased variance; the increased variance and the payment received work in opposition to each other so that, in total, expected utilities in these other countries would not be so much improved. In contrast, the swap between the United States and Far East produces variancereduction benefits for both sides of the swap even without any price payment. The price paid is low; in Table II Panel B the total dollar value of the open interest (the sum of $\beta_{1 c}$ for all countries for which $\beta_{1 c}$ is positive times the price $P_{1}$ ) is only $\$ 31$ billion, about one quarter of one percent of the twelve countries' combined GDP in 1990. This example illustrates the reason that our utility maximization results are basically similar to the corresponding pure variance reduction results (comparing Tables I and II): whenever covariances of country incomes with world income are proportional to country sizes (as measured by $x_{0 c}$ ), then the utility maximization method will produce contracts that are simple swaps at zero price, as with our pure variance reduction method.

The conclusion that the first contract is a US/Far East swap rests on our low estimated covariance between the US, on one side, and Far East on the other; if the US were highly correlated with the Far East, then we might better create a first contract that is a swap between the US and the Far East on one side and other blocks of countries, perhaps Europe, on the other. Alternatively, if one were to use some form of economic distances, rather than geographical distances, in our constrained variance estimation method, then we might possibly, for example, be led to a swap between advanced countries like the United States, Japan, and Europe on one side, and less developed countries, on the other. Such an outcome would require, though, that the correlations among the advanced countries were quite high, otherwise the large scale of these economies would itself tend 
to result in a first market that is a swap among them. Considering such possibilities means making careful adjustments in our estimated variance matrices; the estimates presented here are hardly definitive evidence about the conditional variance matrices that we should hold subjectively today.

If we attach more importance to helping poorer countries, that is, if we follow our utility maximization method to its logical conclusion without imposing any weights in the social welfare function, then the first new market to advocate would appear to be very nearly one for an India/restof-the-world swap, as shown in Table III Panel B. In this case, it hardly matters for contract definition whether the United States and Japan are correlated with each other or not. With this new market, we would expect to see a situation in which all other countries voluntarily share India's risk in proportion to their own national incomes.

One important lesson from our analysis is that there is a great difference between the superficial structure of an optimal contract and the resulting opportunities for risk management that the contract offers. When we allow our method to give (Table III Panel B) great weight to the poorest country, the first market, a swap between India and the world, has the appearance of a market that would serve only India. In fact, however, the (absolute value of the) covariance of real per capita national income with the dividend on this contract is much bigger for the United States than it is for India ${ }^{14}$, and (with our constrained variance matrix results) the US buys more contracts than India sells. The mere fact that we gave so much

\footnotetext{
${ }^{14}$ With our utility-maximizing constrained-variance-matrix results, the correlation coefficient, using $\mathbf{\Omega}$, between US national income and the dividend in the first market is -0.39 , substantially lower in absolute value than the correlation coefficient between India and the dividend in the first market, which is $\mathbf{0 . 8 5}$.
} 
weight to India in our method of designing contracts does not mean that only India benefits. Of course, the markets must offer advantages for richer countries, since even if our method stresses creating markets for the benefit of poorer countries, their counterparts in the richer countries must voluntarily agree to participate in the markets. In the case of the India/ rest-of-world swap, the rest of the world benefits so much that in fact they are willing to pay India, rather than be paid, for bearing India's important (given her low income levels) exposure to risk. That a product could be developed that would go a long way towards solving India's risk problem (reducing her variance by $66.10 \%$ in Table III panel B results) and yet be better than a free good for India is a sort of discovery that we might never have made had we not the benefit of the methods developed here. 
FIGURE 1

Ten Year Growth Rates of Real per capita GDP, Years Ending 1960-90

Source: Computed from data from Summers and Heston (1991), 1950-90.
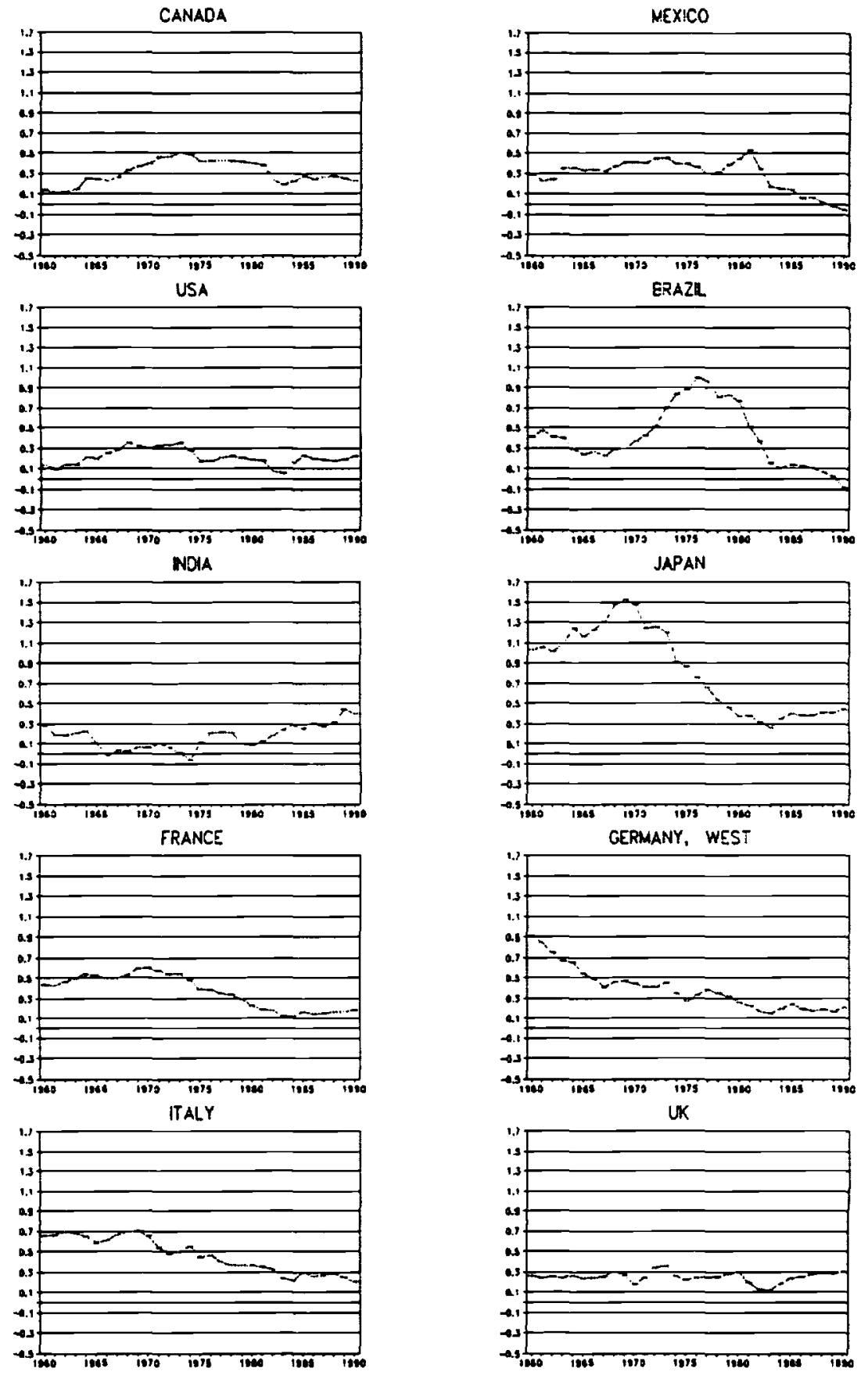
TABLE I

Optimal Securities Designed Using Pure Variance Reduction Method

$$
w=l, \rho=2 \%
$$

\begin{tabular}{|c|c|c|c|c|c|c|}
\hline \multicolumn{7}{|c|}{ A. Unconstrained variance matrix, ten countries, 10-year contracts } \\
\hline \multirow[b]{2}{*}{$c$} & \multicolumn{3}{|c|}{ Market 1} & \multicolumn{3}{|c|}{ Market 2} \\
\hline & $\begin{array}{c}A_{c 1} \\
\text { weights } \\
\times 10^{-10}\end{array}$ & $\begin{array}{c}\beta_{1 c} \\
\text { positions } \\
\times 10^{9}\end{array}$ & $\begin{array}{c}\text { ESS/TSS } \\
\text { benefit } \\
\% \text { of } \sigma^{2}\end{array}$ & $\begin{array}{c}A_{c 2} \\
\text { weights } \\
\times 10^{-10}\end{array}$ & $\begin{array}{c}\beta_{2 c} \\
\text { positions } \\
\times 10^{8}\end{array}$ & $\begin{array}{c}\text { ESS/TSS } \\
\text { benefit } \\
\text { \% of } \sigma^{2}\end{array}$ \\
\hline 1 Canada & .82 & -.20 & 55.00 & 4.01 & -1.09 & 16.54 \\
\hline 2 Mexico & .22 & -.04 & 2.60 & 3.97 & -1.04 & 14.78 \\
\hline 3 USA & 5.26 & -1.34 & 47.42 & 1.06 & 2.76 & 2.01 \\
\hline 4 Brazil & .05 & -.00 & .00 & 8.68 & -7.18 & 79.51 \\
\hline 5 India & -.75 & .21 & 15.99 & 3.01 & .21 & .17 \\
\hline 6 Japan & -1.98 & .52 & 2.75 & -3.05 & 8.12 & 6.68 \\
\hline 7 France & -.30 & .09 & 2.27 & 3.15 & .03 & .00 \\
\hline 8 Germany & -2.29 & .60 & 42.90 & 4.40 & -1.60 & 3.06 \\
\hline 9 Italy & -.82 & .22 & 16.85 & 2.90 & .36 & .44 \\
\hline $10 \mathrm{UK}$ & .26 & -.05 & 6.81 & 3.60 & -.56 & 7.25 \\
\hline
\end{tabular}

B. Constrained variance matrix, twelve countries, 40-year contracts

\begin{tabular}{lrrrrrr}
\hline & \multicolumn{3}{c}{ Market 1 } & \multicolumn{3}{c}{ Market 2 } \\
\cline { 2 - 7 }$c$ & $\begin{array}{c}A_{c 1} \\
\text { weights } \\
\times 10^{-11}\end{array}$ & $\begin{array}{c}\beta_{1 c} \\
\text { positions } \\
\times 10^{10}\end{array}$ & $\begin{array}{c}\text { ESS/TSS } \\
\text { benefit } \\
\% \text { of } \sigma^{2}\end{array}$ & $\begin{array}{c}A_{c 2} \\
\text { weights } \\
\times 10^{-11}\end{array}$ & $\begin{array}{c}\beta_{2 c} \\
\text { positions } \\
\times 10^{10}\end{array}$ & $\begin{array}{r}\text { ESS/TSS } \\
\text { benefit } \\
\%_{0} \sigma^{2}\end{array}$ \\
\hline 1 Canada & -.24 & -.35 & 34.13 & .50 & .06 & .94 \\
2 Mexico & -.32 & -.16 & 7.20 & .54 & .03 & .25 \\
3 USA & 1.38 & -4.12 & 48.20 & -.60 & .91 & 2.37 \\
4 Brazil & -.38 & -.04 & .29 & .65 & -.06 & .61 \\
5 India & -.56 & .39 & 11.64 & .53 & .04 & .10 \\
6 Japan & -.90 & 1.18 & 24.74 & -.63 & .94 & 15.61 \\
7 France & -.44 & .12 & 1.30 & 1.35 & -.60 & 34.90 \\
8 Germany & -.48 & .19 & 2.76 & 1.51 & -.73 & 39.98 \\
9 Italy & -.45 & .14 & 2.20 & 1.27 & -.54 & 32.81 \\
10 UK & -.43 & .10 & .97 & 1.29 & -.56 & 32.89 \\
11 China & -1.28 & 2.06 & 36.51 & -1.67 & 1.75 & 26.13 \\
12 CIS & -.60 & .49 & 5.72 & 2.16 & -1.24 & 36.93 \\
\hline
\end{tabular}

Notes: Weight $A_{c q}, q=1,2$, is fraction of country $c$ detrended GDP paid as part of dividend on one security $q$; position $\beta_{\mathrm{qc}}, q=1,2$, is total number of securities $q$ the theory predicts will be owned in country $c$; ESS/TSS is explained sum of squares over total sum of squares. Source: Calculations by authors using data 1950-1990 from Summers and Heston (1991); see text. 
TABLE II

Optimal Securities Designed Using Utility Maximization Method $w=y_{0}^{\alpha} x_{0}, \rho=2 \%, \alpha=3, g=3.07 \%$

A. Unconstrained variance matrix, ten countries, 10-year contracts

\begin{tabular}{|c|c|c|c|c|c|c|}
\hline \multirow[b]{2}{*}{$c$} & \multicolumn{3}{|c|}{ Market 1, Price $=\$ 46.33$} & \multicolumn{3}{|c|}{ Market 2, Price $=\$ 20.50$} \\
\hline & $\begin{array}{c}\bar{A}_{c 1} \\
\text { weights } \\
\times 10^{-9}\end{array}$ & $\begin{array}{c}\bar{\beta}_{1 c} \\
\text { positions } \\
\times 10^{8}\end{array}$ & $\begin{array}{c}\text { Consumer } \\
\text { surplus } \\
\% \text { of GDP }\end{array}$ & $\begin{array}{c}A_{c 2} \\
\text { weights } \\
\times 10^{-9}\end{array}$ & $\begin{array}{c}\bar{\beta}_{2 c} \\
\text { positions } \\
\times 10^{8}\end{array}$ & $\begin{array}{l}\text { Consumer } \\
\text { surplus } \\
\% \text { of GDP }\end{array}$ \\
\hline 1 Canada & -.05 & -.56 & 2.25 & .67 & .07 & .04 \\
\hline 2 Mexico & -.16 & .02 & .00 & .96 & -.31 & .69 \\
\hline 3 USA & .64 & -4.20 & 1.26 & -1.15 & 2.45 & .43 \\
\hline 4 Brazil & -.12 & -.20 & .17 & 1.72 & -1.30 & 7.69 \\
\hline 5 India & .13 & -1.50 & 4.30 & 1.42 & -.91 & 1.56 \\
\hline 6 Japan & -1.21 & 5.57 & 13.97 & -.59 & 1.71 & 1.32 \\
\hline 7 France & -.26 & .52 & .67 & .79 & -.09 & .02 \\
\hline 8 Germany & -.27 & .61 & .71 & 1.62 & -1.17 & 2.57 \\
\hline 9 Italy & -.26 & .55 & .86 & .97 & -.33 & .30 \\
\hline $10 \mathrm{UK}$ & -.00 & -.82 & 1.79 & .82 & -.13 & .05 \\
\hline
\end{tabular}

B. Constrained variance matrix, twelve countries, 40-year contracts

\begin{tabular}{|c|c|c|c|c|c|c|}
\hline \multirow[b]{2}{*}{ c } & \multicolumn{3}{|c|}{ Market 1, Price $=\$ 14.42$} & \multicolumn{3}{|c|}{ Market 2 , Price $=\$ 6.41$} \\
\hline & $\begin{array}{c}A_{c 1} \\
\text { weights } \\
\times 10^{-10} \\
\end{array}$ & $\begin{array}{c}\boldsymbol{\beta}_{1 c} \\
\text { positions } \\
\times 10^{9} \\
\end{array}$ & $\begin{array}{c}\text { Consumer } \\
\text { surplus } \\
\% \text { of GDP }\end{array}$ & $\begin{array}{c}\boldsymbol{A}_{c^{2}} \\
\text { weights } \\
\times 10^{-10} \\
\end{array}$ & $\begin{array}{c}\boldsymbol{\beta}_{2 c} \\
\text { positions } \\
\times 10^{8} \\
\end{array}$ & $\begin{array}{c}\text { Consumer } \\
\text { surplus } \\
\% \text { of GDP }\end{array}$ \\
\hline 1 Canada & .29 & .16 & 17.37 & 1.01 & .22 & .36 \\
\hline 2 Mexico & .49 & .05 & 1.95 & 1.13 & .02 & .00 \\
\hline 3 USA & -3.25 & 1.95 & 27.14 & -1.29 & 4.04 & 1.17 \\
\hline 4 Brazil & .61 & -.01 & .03 & 1.38 & -.40 & .72 \\
\hline 5 India & .95 & -.18 & 6.26 & 1.10 & .07 & .01 \\
\hline 6 Japan & 1.64 & -.53 & 12.52 & -1.30 & 4.06 & 7.41 \\
\hline 7 France & .72 & -.06 & .95 & 2.76 & -2.68 & 17.55 \\
\hline 8 Germany & .78 & -.10 & 1.71 & 3.11 & -3.27 & 20.17 \\
\hline 9 Italy & .74 & -.07 & 1.50 & 2.58 & -2.38 & 16.21 \\
\hline $10 \mathrm{UK}$ & .70 & -.05 & .76 & 2.64 & -2.48 & 16.54 \\
\hline 11 China & 2.42 & -.93 & 18.50 & -3.95 & 8.45 & 15.43 \\
\hline 12 CIS & 1.05 & -.23 & 3.19 & 4.55 & -5.65 & 19.44 \\
\hline
\end{tabular}

Notes: Weight $\bar{A}_{c q}, q=1,2$, is fraction of country $c$ detrended GDP paid as part of dividend on one security $q$; position $\bar{\beta}_{\mathrm{q} c}, q=1,2$, is total number of securities $q$ the theory predicts will be owned in country $c$; consumer surpluses, dollar value of expected utility gained (utility of the $T$ years' income) as a fraction of the first year's GDP, are defined from positions using (26). Source: See Table I. 
TABLE III

Optimal Securities Designed Using Utility Maximization Method

$$
w=I, \rho=2 \%, \alpha=3, g=3.07 \%
$$

A. Unconstrained variance matrix, ten countries, 10-year contracts

\begin{tabular}{|c|c|c|c|c|c|c|}
\hline \multirow[b]{2}{*}{$c$} & \multicolumn{3}{|c|}{ Market 1, Price $=\$ 48.17$} & \multicolumn{3}{|c|}{ Market 2, Price $=\$ 8.16$} \\
\hline & $\begin{array}{c}\bar{A}_{c 1} \\
\text { weights } \\
\times 10^{-9} \\
\end{array}$ & $\begin{array}{c}\overline{\boldsymbol{\beta}}_{1 c} \\
\text { positions } \\
\times 10^{8}\end{array}$ & $\begin{array}{c}\text { Consumer } \\
\text { surplus } \\
\% \text { of GDP }\end{array}$ & $\begin{array}{c}\bar{A}_{c 2} \\
\text { weights } \\
\times 10^{-9} \\
\end{array}$ & $\begin{array}{c}\overline{\boldsymbol{\beta}}_{2 c} \\
\text { positions } \\
\times 10^{8} \\
\end{array}$ & $\begin{array}{c}\text { Consumer } \\
\text { surplus } \\
\% \text { of GDP }\end{array}$ \\
\hline 1 Canada & -.32 & -.15 & .17 & -.25 & -.30 & .66 \\
\hline 2 Mexico & -.32 & .18 & .24 & .20 & -.40 & 1.18 \\
\hline 3 USA & -.32 & -1.65 & .20 & -.26 & 1.00 & .07 \\
\hline 4 Brazil & -.32 & .09 & .04 & 4.52 & -2.04 & 18.88 \\
\hline 5 India & 3.96 & -2.33 & 10.34 & -.08 & -.00 & .00 \\
\hline 6 Japan & -.32 & 4.10 & 7.56 & -.28 & 1.92 & 1.65 \\
\hline 7 France & -.32 & .36 & .32 & -.26 & -.03 & .00 \\
\hline 8 Germany & -.32 & -.14 & .04 & -.26 & -.07 & .01 \\
\hline 9 Italy & -.32 & .21 & .13 & -.26 & .01 & .00 \\
\hline $10 \mathrm{UK}$ & -.32 & -.67 & 1.22 & -.25 & -.09 & .02 \\
\hline
\end{tabular}

B. Constrained variance matrix, twelve countries, 40-year contracts

\begin{tabular}{lrrrrrr}
\hline & \multicolumn{3}{c}{ Market 1, Price $=\$ 16.89$} & \multicolumn{3}{c}{ Market 2, Price $=\$ 3.80$} \\
\cline { 2 - 7 } & $\begin{array}{c}\bar{A}_{c 1} \\
\text { weights } \\
\times 10^{-9}\end{array}$ & $\begin{array}{c}\bar{\beta}_{1 c} \\
\text { positions } \\
\times 10^{8}\end{array}$ & $\begin{array}{c}\text { Consumer } \\
\text { surplus } \\
\text { \% of GDP }\end{array}$ & $\begin{array}{c}\bar{A}_{c 2} \\
\text { weights } \\
\times 10^{-10}\end{array}$ & $\begin{array}{c}\bar{\beta}_{2 c} \\
\text { positions } \\
\times 10^{9}\end{array}$ & $\begin{array}{c}\text { Consumer } \\
\text { surplus }\end{array}$ \\
\% of GDP \\
\hline 1 Canada & -.12 & .66 & 3.14 & .91 & -.08 & 4.49 \\
2 Mexico & -.12 & .22 & .35 & 1.02 & -.04 & 1.30 \\
3 USA & -.12 & 7.79 & 4.34 & .91 & -.89 & 5.64 \\
4 Brazil & -.12 & -.05 & .01 & 1.16 & -.04 & .84 \\
5 India & 1.84 & -5.02 & 47.43 & 6.88 & -.03 & .20 \\
6 Japan & -.12 & -1.11 & .55 & .89 & .42 & 7.87 \\
7 France & -.12 & .49 & .58 & .91 & -.11 & 3.01 \\
8 Germany & -.12 & .43 & .34 & .91 & -.12 & 2.76 \\
9 Italy & -.12 & .22 & .14 & .92 & -.98 & 2.50 \\
10 UK & -.12 & .49 & .63 & .92 & -.11 & 2.97 \\
11 China & -.07 & -3.88 & 3.25 & -6.81 & 1.26 & 34.53 \\
12 CIS & -.12 & -.24 & .03 & 1.04 & -.17 & 1.72 \\
\hline
\end{tabular}

Note: See Notes to Table II. 
TABLE IV

Optimal Securities Designed Using Utility Maximization Method

$$
w=y_{0}^{\alpha} x_{0}, \rho=2 \%, \alpha=3, g=0 \%
$$

A. Unconstrained variance matrix, ten countries, 10-year contracts

\begin{tabular}{|c|c|c|c|c|c|c|}
\hline \multirow[b]{2}{*}{$c$} & \multicolumn{3}{|c|}{ Market 1 , Price $=\$ 56.71$} & \multicolumn{3}{|c|}{ Market 2, Price $=\$ 20.07$} \\
\hline & $\begin{array}{c}\bar{A}_{c 1} \\
\text { weights } \\
\times 10^{-10}\end{array}$ & $\begin{array}{c}\bar{\beta}_{1 c} \\
\text { positions } \\
\times 10^{8}\end{array}$ & $\begin{array}{l}\text { Consumer } \\
\text { surplus } \\
\% \text { of GDP }\end{array}$ & $\begin{array}{c}\bar{A}_{\mathrm{c} 2} \\
\text { weights } \\
\times 10^{-9}\end{array}$ & $\begin{array}{c}\bar{\beta}_{2 c} \\
\text { positions } \\
\times 10^{8}\end{array}$ & $\begin{array}{c}\text { Consumer } \\
\text { surplus } \\
\% \text { of GDP }\end{array}$ \\
\hline 1 Canada & -.27 & -.87 & 5.48 & .44 & .12 & .11 \\
\hline 2 Mexico & -.91 & -.02 & .00 & .64 & -.48 & 1.63 \\
\hline 3 USA & 3.87 & -6.41 & 2.94 & -.78 & 3.78 & 1.02 \\
\hline 4 Brazil & -.61 & -.41 & .78 & 1.15 & -2.03 & 18.71 \\
\hline 5 India & .98 & -2.54 & 12.23 & .87 & -1.18 & 2.65 \\
\hline 6 Japan & -7.67 & 9.02 & 36.56 & -.35 & 2.50 & 2.81 \\
\hline 7 France & -1.53 & .81 & 1.59 & .53 & -.15 & .06 \\
\hline 8 Germany & -1.61 & .92 & 1.58 & 1.10 & -1.87 & 6.61 \\
\hline 9 Italy & -1.54 & .82 & 1.93 & .65 & -.52 & .79 \\
\hline $10 \mathrm{UK}$ & .05 & -1.30 & 4.54 & .53 & -.16 & .07 \\
\hline
\end{tabular}

B. Constrained variance matrix, twelve countries, 40-year contracts

\begin{tabular}{|c|c|c|c|c|c|c|}
\hline \multirow[b]{2}{*}{$c$} & \multicolumn{3}{|c|}{ Market 1 , Price $=\$ 42.62$} & \multicolumn{3}{|c|}{ Market 2, Price $=\$ 20.18$} \\
\hline & $\begin{array}{c}\bar{A}_{c 1} \\
\text { weights } \\
\times 10^{-11} \\
\end{array}$ & $\begin{array}{c}\bar{\beta}_{1 c} \\
\text { positions } \\
\times 10^{10} \\
\end{array}$ & $\begin{array}{c}\text { Consumer } \\
\text { surplus } \\
\% \text { of GDP }\end{array}$ & $\begin{array}{c}\bar{A}_{\mathrm{c} 2} \\
\text { weights } \\
\times 10^{-11} \\
\end{array}$ & $\begin{array}{c}\bar{\beta}_{2 c} \\
\text { positions } \\
\times 10^{9} \\
\end{array}$ & $\begin{array}{c}\text { Consumer } \\
\text { surplus } \\
\% \text { of GDP }\end{array}$ \\
\hline 1 Canada & .41 & .11 & 884.56 & 1.41 & .16 & 18.68 \\
\hline 2 Mexico & .72 & .03 & 84.44 & 1.60 & .01 & .03 \\
\hline 3 USA & -4.64 & 1.37 & $1,343.49$ & -1.76 & 2.79 & 55.86 \\
\hline 4 Brazil & .90 & -.01 & 4.96 & 1.90 & -.25 & 28.15 \\
\hline 5 India & 1.35 & -.12 & 283.20 & 1.53 & .06 & .67 \\
\hline 6 Japan & 2.33 & -.37 & 607.44 & -1.85 & 2.87 & 370.58 \\
\hline 7 France & 1.05 & -.05 & 54.65 & 3.88 & -1.89 & 877.19 \\
\hline 8 Germany & 1.14 & -.07 & 92.62 & 4.40 & -2.32 & $1,015.38$ \\
\hline 9 Italy & 1.07 & -.05 & 81.74 & 3.62 & -1.67 & 805.81 \\
\hline $10 \mathrm{UK}$ & 1.02 & -.04 & 44.10 & 3.72 & -1.76 & 828.15 \\
\hline 11 China & 3.43 & -.64 & 888.78 & -5.63 & 6.01 & 779.60 \\
\hline 12 CIS & 1.51 & -.16 & 161.93 & 6.42 & -4.00 & 975.29 \\
\hline
\end{tabular}

Note: See Notes to Table II. 
Symbol List

Note: Matrices and vectors are represented as bold-faced symbols, scalars are not bolded.

\section{A. Latin Symbols}

A $C \times Q$ matrix whose $c q$ th element is the share of country $c$ 's income that is included in the dividend paid on income component security $q$.

c Country number; countries are ordered and each is given a number $c$, these numbers range from 1 to $C$.

C Total number of countries studied here.

D $C \times C$ matrix constructed so that for any $C \times 1$ element vector $x D x$ equals the demeaned vector $x$, that is, a vector whose $c$ th element equal to $x_{c}$ minus the mean of the $C$ elements of $x$.

$F \quad Q \times C$ matrix, $F_{q c}$ is the dollar value for country $c$ of the utility increase achieved by establishing market $q$, as a fraction of its baseyear income.

$\boldsymbol{g}$ Anticipated growth rate of real per capita gross domestic product.

$G \quad C \times C$ diagonal matrix whose th diagonal element equals $\left((1+\rho)(1+g)^{\alpha+1}\right)^{-t}$.

$M C \times C$ matrix such that $X M$ is the vector of regression residuals; the $c$ th element of $X M$ is the residual in a regression of country $c$ 's income on world income.

$\bar{M} C \times C$ matrix such that $X \bar{M}$ is the vector of excess national incomes over each countries' share in world income; the cth element of $X M$ is the income of country $c$ minus $c$ 's share in world income, the latter defined as world income times $x_{0 c}\left(\Sigma\left(c=1, \ldots, C x_{0 c}\right)\right.$.

$P \quad Q \times 1$ vector whose $q$ th element is the price of income component security $q$, i.e., the amount that is paid each year, $t=1, \ldots, T$, according to the contract at time 0 from longs in the contract to the shorts; elements can be both positive or negative. 
$Q$ Number of markets for income component securities defined here; i.e., the number of distinct contract types available for use in risk management.

$\boldsymbol{R}$ In pure variance reduction case (section I of paper), a $1 \times Q$ vector, whose $q$ th element is the total dividends, over $T$ years, paid by income component security $q$. In the utility case maximization case (Section II of paper), a $T \times Q$ matrix, whose tqth element is the total dividends paid in year $t$ by contract $q$. In both cases, $R=X A$.

$S$ Social welfare; in pure variance reduction case (Section I of paper) it is a weighted sum of variances. In the utility maximization case (Section II of paper) it is a weighted sum of utilities.

$t$ Year, contract year is 0 , first year following contract is 1 .

$T$ Number of years in contract; contract pays dividends from year 1 to year $T$.

$\tau$ Present value of $T$-year annuity paying $\$ 1$ each year using discount factor $v=1 /\left((1+\rho)(1+g)^{\alpha-1}\right)$, so that $\tilde{T}=\left(v-v^{T+1}\right) /(1-v)$. With $g=3.07 \%$ and $\rho=2 \%, T=10$ gives $\tilde{T}=6.60, T=40$ gives $\tilde{T}=11.48$; changing $g$ to $0, T=10$ gives $T=8.98, T=40$ gives $\tilde{T}=27.36$.

$u_{t c}$ Felicity, at year $t$, of country $c$.

$U_{c}$ Utility of country $c$, the present value from 1 to $T$ of felicities $u_{t c}$.

w $C \times C$ diagonal matrix, whose $c$ th diagonal element is the weight given to country $c$ by the contract designer in the social welfare function used to derive the optimal income component securities.

$x_{0 c}$ National income of country $c$ at the point of linearization at year 0 for the felicity function, nonstochastic. In our data, $x_{0 c}$ is gross domestic product (total, not per capita) of country $c$ in 1990, measured in 1985 dollars; for the CIS, 1989 gross domestic product was used.

$x_{0} C \times C$ diagonal matrix, whose $c$ th diagonal element is $x_{0 c}$. 
$X$ In the pure variance reduction case (Section $I$ of the paper), $X$ is a $1 \times C$ vector whose $c$ th element is the demeaned present value of real per capita income (gdp), from years 1 through $T$, of country $c$, discounted by $\rho$, and multiplied by population of country $c$ in year 0 . In the utility maximization case (Section II of the paper), $X$ is the $T \times C$ matrix whose tcth element is demeaned real per capita income of country $c$ at year $t$ multiplied by population in year 0 .

$y_{0 c}$ Per capita income at time 0 in country $c$, equal to $x_{0 c}$ divided by population at time 0 of country $c$.

$y_{0} C \times C$ diagonal matrix, whose $c$ th diagonal element is $y_{0 c}$.

\section{B. Greek Symbols}

$\alpha$ Risk aversion parameter, assumed to be the same for all countries.

B $Q \times C$ matrix whose $q$ cth element is the total number of the $q$ th income component securities demanded by individuals in country $c$.

$\gamma \quad C \times 1$ vector whose $c$ th element is the slope coefficient in a regression of country $c$ 's income on total world income

$\bar{\gamma} \quad C \times 1$ vector whose $c$ th element is the share of country $c$ 's income in total world income in the base year.

1 $C \times 1$ vector, all of whose elements equal one.

$\lambda_{q}$ A Lagrangian multiplier for the contract designer's problem, corresponding to the constraint that $A_{q}{ }^{\prime} \mathbf{D} A_{q}=1$, where $A_{q}$ is the $q$ th column of $A$; also the qth eigenvalue of a matrix defined in that problem.

$\Lambda \quad Q \times Q$ diagonal matrix, whose $q$ th diagonal element is $\lambda_{q}$.

$\mu \quad Q \times 1$ vector, whose elements are Lagrangian multipliers for the constraints that the $Q$ markets clear.

$\rho$ Subjective rate of time preference in utility function. 
a $\quad C \times C$ matrix. In the pure variance reduction case (Section II of paper) this is the variance, conditional on information at year 0 , of the present value of income from year 1 to $T$. In the utility maximization case (Section III of paper) $\mathbb{Q}$ is $E_{0} X^{\prime} G X$.

0, $C \times C$ matrix, the variance, conditional on information at year 0 , of real per capita income in year $t$ times population in year 0 . 
Comparison of Basic Relations

As Between Pure Variance Reduction and Utility Maximization Cases

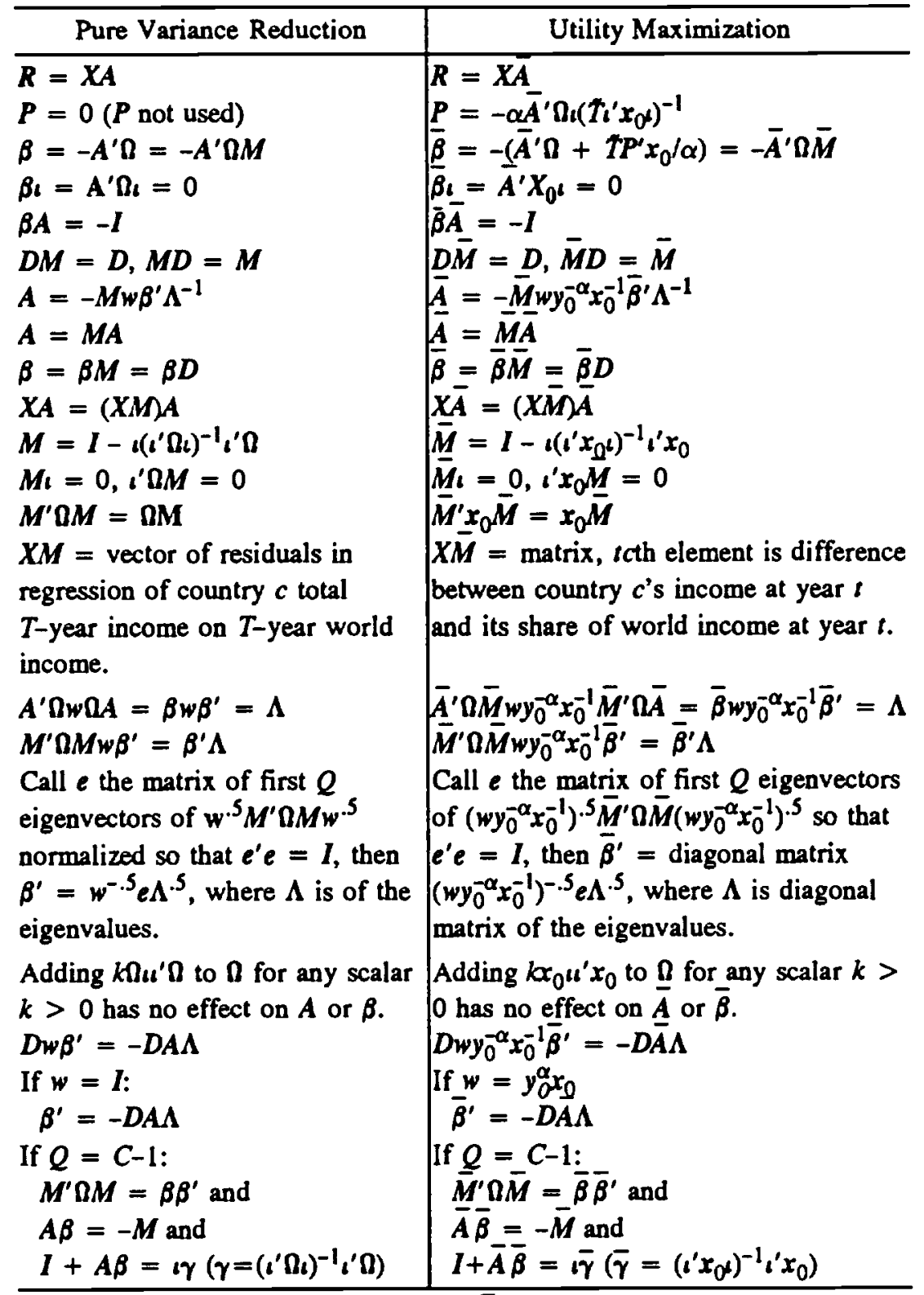

If $\mathrm{a} \propto$ (proportional to) $x_{0}$, then $M=\bar{M}$ and $P=0$. More generally $\iota^{\prime} \Omega \propto$ ' $x_{0}$ (sum columns proportional) iff $M=\bar{M}$. If $M=\bar{M}$ then $P=0$. 


\section{REFERENCES}

Arrow, Kenneth J. (1964). "The Role of Securities in the Optimal Allocation of Risk Bearing," Review of Economic Studies, 31: 91-96.

Athanasoulis, Stefano (1994). "Marketing Nontraded Risks," unpublished paper, Yale University.

Atkeson, Andrew, and Tamim Bayoumi (1991). "Do Private Capital Markets Insure against Risks in a Common Currency Area? Evidence from the United States," unpublished paper, University of Chicago.

Atkeson, Andrew, and Christopher Phelan (1994). "Reconsidering the Costs of Business Cycles with Incomplete Markets." In NBER Macroeconomics Annual 1994. Cambridge, MA: MIT Press, pp. 187-206.

Baxter, Marianne, Urban J. Jermann, and Robert G. King (1994). "Nontraded Goods, Nontraded Factors, and International Non-Diversification," xeroxed, University of Virginia.

Brennan, Michael J., and Bruno Solnik (1989). "International Risk Sharing and Capital Mobility," Journal of International Money and Finance, 8: 359-373.

Cole, Harold L., and Maurice Obstfeld (1991). "Commodity Trade and International Risk Sharing: How Much Do Financial Markets Matter?" Journal of Monetary Economics, 28: 3-24.

Cressie, Noel (1991). Statistics for Spatial Data. New York: WileyInterscience.

Duffie, Darrell, and Matthew O. Jackson (1989). "Optimal Innovation of Futures Contracts, " Review of Financial Studies, 2: 275-296.

Grossman, Gene M., and Elhanan Helpman (1991). Innovation and Growth in the Global Economy. Cambridge, MA: MIT Press.

Kapner, Kenneth R., and John F. Marshall (1990). The Swaps Handbook. New York: New York Institute of Finance.

Mehra, Rajnish, and Edward C. Prescott (1985). "The Equity Premium: A Puzzle," Journal of Monetary Economics, 15: 145-161. 
Obstfeld, Maurice (1992). "International Risk Sharing and Capital Mobility: Another Look," Journal of International Money and Finance, 11: 115-121.

Obstfeld, Maurice (1993). "Are Industrial Country Consumption Risks Globally Diversified?" National Bureau of Economic Research Working Paper No. 4308.

Obstfeld, Maurice (1994a). "Evaluating Risky Consumption Paths: The Role of Intertemporal Substitutability," European Economic Review, 38: 1471-1486.

Obstfeld, Maurice (1994b). "International Capital Mobility in the 1990s," International Finance Discussion Paper Series, Board of Governors of the Federal Reserve System, No. 472, June.

Obstfeld, Maurice (1995). "Risk-Taking, Global Diversification, and Growth," forthcoming in American Economic Review.

Pigou, A. C. (1934). Economics of Welfare. London: Macmillan.

Quah, Danny, and Thomas J. Sargent (1993). "A Dynamic Index Model for Large Cross Sections." In James Stock and Mark Watson (eds.), Business Cycles, Indicators, and Forecasting, Chicago: NBER, University of Chicago Press.

Romer, Paul M. (1990). "Endogenous Technological Change," Journal of Political Economy, Part II, 98(5): S71-S102.

Sargent, Thomas J., and Christopher A. Sims (1977). "Business Cycle Modelling without Pretending to Have Too Much a priori Economic Theory." In in Christopher A. Sims (ed.), New Methods in Business Cycle Research. Minneapolis: Federal Reserve Bank of Minneapolis.

Shiller, Robert J. (1993a). Macro Markets: Creating Institutions for Managing Society's Largest Economic Risks. Oxford: Oxford University Press, Oxford.

Shiller, Robert J. (1993b). "Measuring Asset Values for Cash Settlement in Derivative Markets: Hedonic Repeated Measures Indices and Perpetual Futures," Journal of Finance, July. 
Summers, Robert, and Alan Heston (1991). "The Penn World Table (Mark 5): An Expanded Set of International Comparisons, " Quarterly Journal of Economics, 106: 1-41.

Thaler, Richard H. (1990). "Anomalies, Saving, Fungibility and Mental Accounts," Journal of Economic Perspectives, 4: 193-206, Winter. 